\title{
An Analysis and Synthesis of Research on Classroom Peer Tutoring Methods that Benefit Intermediate Math Students
}

Shelley R. Grimm

Cedarville University

Follow this and additional works at: http://digitalcommons.cedarville.edu/education theses

Part of the Science and Mathematics Education Commons

\section{Recommended Citation}

Grimm, Shelley R., "An Analysis and Synthesis of Research on Classroom Peer Tutoring Methods that Benefit Intermediate Math Students" (2004). Master of Education Research Theses. 9.

http://digitalcommons.cedarville.edu/education_theses/9 


\section{AN ANALYSIS AND SYNTHESIS OF RESEARCH ON \\ CLASSROOM PEER TUTORING METHODS THAT BENEFIT INTERMEDIATE \\ MATH STUDENTS}

A thesis submitted in partial fulfillment

of the requirements for the degree of

Masters of Education

By

SHELLEY RENEE GRIMM

B.A., Malone College, 1997

B.S., Malone College, 1998

2004

Cedarville University 


\section{CEDARVILLE UNIVERSITY \\ SCHOOL OF GRADUATE STUDIES}

May 1, 2004

I HEREBY RECOMMEND THAT THE THESIS PREPARED UNDER MY SUPERVISION BY Shelley Renee Grimm ENTITLED An Analysis and Synthesis of Research on Classroom Peer Tutoring Methods that Benefit Intermediate Math Students BE ACCEPTED IN PARTIAL FULFILLMENT OF THE REQUIREMENTS FOR THE DEGREE OF Masters of Education.

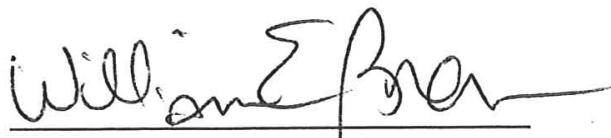

William E. Brown, Ph. D.

President

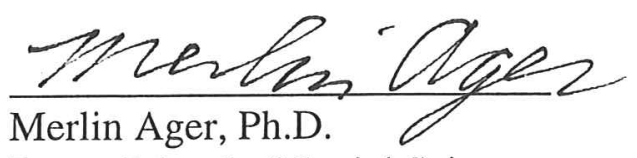

Dean, School of Social Sciences and Professional Studies
DumneR. Word

Duane R. Wood, D.B.A.

Academic Vice President

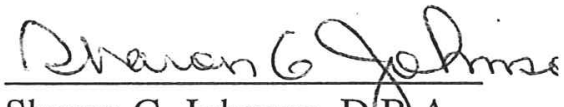

Sharon G. Johnson, D.B.A.

Director of Graduate Programs

Stephen S. Gruber, Ed.D.

Education Department Chair

Thesis Advisor 


\begin{abstract}
Grimm, Shelley Renee. M.Ed. Education Department, Cedarville University, 2004. An Analysis and Synthesis of Research on Classroom Peer Tutoring Methods that Benefit Intermediate Math Students.
\end{abstract}

What are the benefits of peer tutoring? What do productive peer tutoring sessions include? This study occurred in fourth and fifth grade classrooms at a private school in a rural community. The researcher conducted an experiment to determine if students benefited from the opportunity to have their fellow students tutor them and elaborate on their method of problems solving during math class. In light of the inconsistent results, the author believes no assumptions can be made based on the data from this research. The fourth grade results showed definite progress according to the standardized test, but there was some inconsistency in the achievement shown in the classroom tests. The fifth grade results did not show a significant growth from fourth to fifth grade on the math portion of the achievement test. There is also inconsistency in the significance of the growth in learning shown in the fifth grade classroom tests. However, the researcher hopes this study will encourage further exploration in the study of beneficial peer tutoring methods. 
TABLE OF CONTENTS

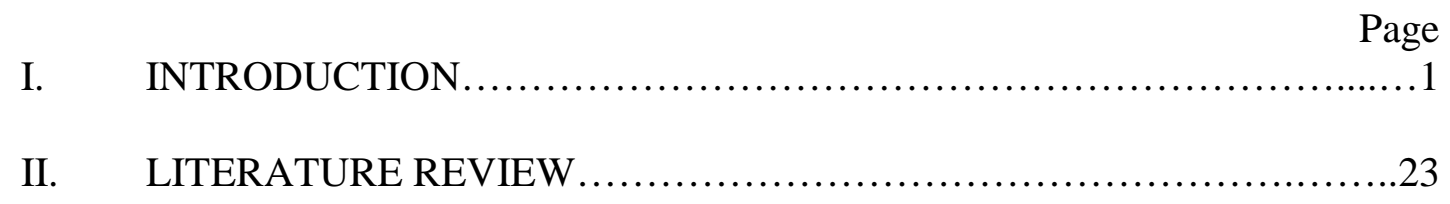

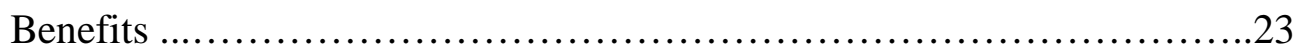

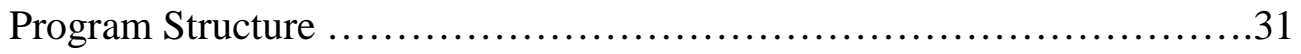

Motivation ....................................................... 46

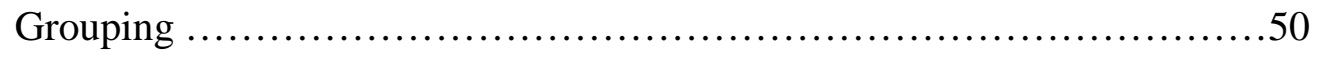

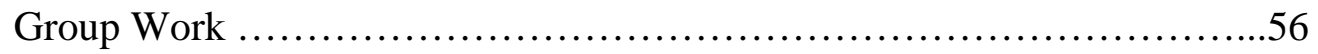

III. THE PROJECT AND RESULTS .......................................73

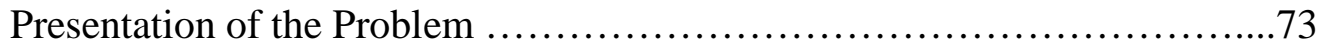

Presentation of the Hypothesis ........................................... 75

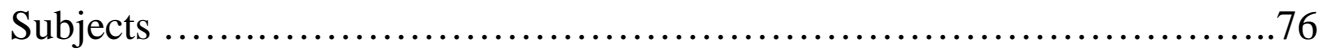

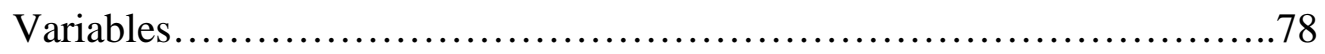

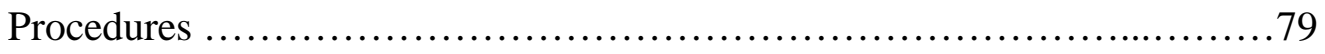

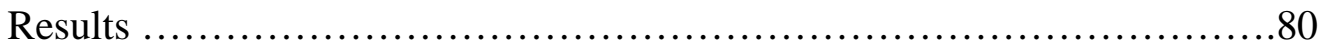

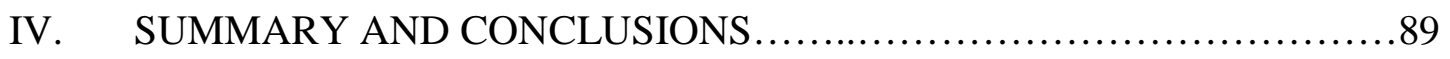

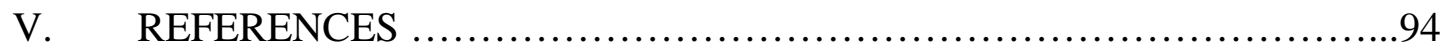

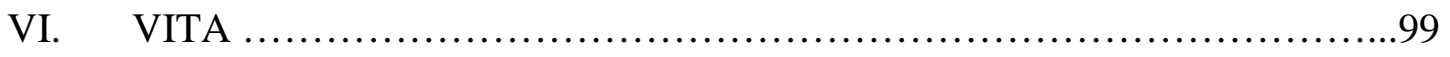




\section{ACKNOWLEDGEMENTS}

Special thanks to Dr. Gruber for his patience and help throughout this process.

I am also thankful for my high school math teacher, Mrs. Clason, who proofread Chapter III for me. Her kindness was a great blessing to me as I neared the end of the project.

I owe so much to my family and my friends, especially Terry and Linda. They encouraged me not to give up and complete this great task. 


\section{Chapter I: INTRODUCTION}

\section{Educational Significance}

Peer tutoring is beneficial for both the tutor and the tutee (Mevarich, 1985). Elementary students working in pairs participate in a far more superior mathematics learning experience than those who sit in classrooms where the teacher lectures (Fuchs et al., 1997). Studies show that underachieving students are better able to understand their peer’s explanation than they comprehend the teacher or the book (Mevarich, 1985). However, it must be structured to ensure consistent benefit to the parties involved (Webb, 1991).

\section{Purpose}

The object of this study is to discover the best possible peer tutoring environment for mathematics. The goal is to teach the students to work together in a balanced manner that benefits students at all levels from high, middle, and lower ends of the achievement curve and to increase testing scores as well. The examination of articles will uncover the elements of effective cooperative learning work and lead to a successful classroom program design. This design will be tested and the results shown. The educational goal is to enable teachers to better utilize their time by allowing stronger students to help the weaker ones. 


\section{Research Questions}

This will add to the achievement of the special needs students and the memory retention of the stronger ones. Teachers will be able to meet the needs of their students in a more efficient manner by offering answers to the questions unanswered by the collective knowledge of the group as they search the text. In order to accomplish this, two questions must be answered. First of all, what are the benefits of peer tutoring? Second, what do productive peer tutoring sessions include?

\section{Definitions}

Certain terms used in this study may be used with a slightly different connotation than traditionally used. For the purposes of this study, peer tutoring will mean pairs of students available to answer each other's questions on a problem set in an efficient method. The teacher circulates to respond to any questions students might have that their group may not answer. Teams are working together to learn something (Slavin, 1987). Everyone must understand the concept to maximize the potential of reaching his or her goal (Slavin, 1987).

\section{Integration}

As human beings we were created to live in community. Adam was given Eve in Genesis 2 and the New Testament Church was encouraged to work to the benefit of their brothers and sisters in Christ (Ephesians 4:15,16; Philippians 2:3,4). There is a healthy balance between the requirement of individual effort and helping each other in time of 
need. Paul recognizes this when he states that those who wish to eat must work (II Thessalonians 3:10).

Like the Christian walk, learning an academic concept takes work. We need the fellowship of others to help us reach success in this area. This help should be something that encourages us and enables us to attempt greater things. It should help build confidence with out fostering an unhealthy laziness or dependence.

\section{Application to Current School}

The recognition of a need for additional math help for the researcher's students led her to try different methods to increase achievement. Analyzing data and combining the wisdom of several experts in the area of cooperative learning have helped in the understanding of the basic components of a good math program that uses group work. The goal of this project was to test the benefits of using a structured cooperative learning program in mathematics in a Christian school located in a rural setting.

\section{Summary}

This project seeks to establish a well-balanced program that enables all students to do their best at learning math and maximize teacher effectiveness in increasing mathematics learning. In the process, the study is designed to understand the pitfalls of peer tutoring in mathematics and solve those issues. 


\section{LITERATURE REVIEW}

Definition:

Cooperative Learning happens in a small group setting where students share ideas and work together to accomplish school work (Davidson and Kroll, 1991). Cooperative learning diverges from traditional methods that are based on personal performance and competition (Davidson and Kroll, 1991).

There are potential problems with individualized programs. First, they require self-discipline, self-confidence, motivation, and ability to work alone. Individualized programs also require strong reading skills. If the program is not a good fit and the children do not have the necessary skills, they fail (Endsley, 1980). Upper to middle socioeconomic status students do well with an individualized system. However, those who are of lower socioeconomic status tend to work better in cooperative learning situations. These students who struggle academically may need to build "self efficacy" through the use of cooperative learning (Griffin and Griffin, 1998).

There are many types of cooperative learning groups that can be clearly defined (Davidson and Kroll, 1991) In this study, we are focusing on cooperative learning using peer tutoring. Johnson et al. found that cooperative learning encouraged "achievement and productivity” (Davidson and Kroll, 1991; Griffin and Griffin, 1998). Actually, this is significantly true in less than half of the studies done prior to 1991; they either favor cooperative learning or they are inconclusive because of unforeseen variables (Davidson and Kroll, 1991; Griffin and Griffin, 1998). Webb believes that by analyzing the types 
of feedback and questions occurring in the group setting, cooperative learning can be structured in a way that benefits all students in a statistically significant way (1991). She believes that the inconclusive data comes from research that has not considered the group conversation (Webb, 1991).

Developing a peer-tutoring program requires great effort to prepare and implement the system (Endsley, 1980; Griffin and Griffin, 1998). Students must be selected and paired with suitable partners (Endsley, 1980). The tutors must be selected and trained (Endsley, 1980). Specific goals and objectives must be outlined and pre/posttests must be set up in an observable, measurable manner (Endsley, 1980; Griffin and Griffin, 1998). Student record keeping forms and procedures in order to process data must be created (Endsley, 1980). Tutor log, schedule, and assignment sheets need to be created so that records may be kept (Endsley, 1980). Instructional materials including assignments, reviews, posttests, and summative learning activities must also be developed and structured (Endsley, 1980; Griffin and Griffin, 1998).

To participate in the study, these students can not be tutored in the subject matter or have been exposed to peer-tutoring programs in the content area being examined (C. Utay and J. Utay, 1997). Participants can be divided into several groups. High ability students are in the top $25 \%$ of the sample. Medium ability students are people between the top and bottom $25 \%$ of the sample. Low ability students are people in the bottom 25\% of the sample. Learning Disabled Students must have at least average intelligence 
and qualities that make them match the federal definition of a learning disability (C. Utay and J. Utay, 1997).

There are a variety of ways students can work together. Types of peer tutoring include Reciprocal Peer Tutoring, Peer Assisted Learning Strategies, and Cross-Age Peer Tutoring. Reciprocal Peer Tutoring is peer tutoring that lets both students be the teacher and gain strength from learning to express knowledge to another student (Griffin and Griffin, 1998). (PALS) Peer Assisted Learning Strategies is a two person group that helps students who differ in their level of mathematical success (Fuchs, Fuchs, and Karns, 2001). It establishes mixed ability groups. Cross-Age Peer Tutoring is similar in that it lets students help those who are younger (C. Utay and J. Utay, 1997).

Mastery Learning ensures that no student misses a concept (Mevarich, 1985). They all must reach $80 \%$ accuracy or above. The teacher tests and retests to check progress (Mevarich, 1985) When combined with cooperative learning, it is called Student Team Mastery Learning (STML). STML has students learn together in groups and them tests them to reveals areas in need of improvement. Those who excel help the ones who are struggling to achieve mastery according to Mevarich (1985). This should benefit all students (Mevarich, 1985). Fasko (1994) suggests using this to teach multiplication facts.

In the learning process, the type of task varies. In a single-answer task, students must find one right answer. Discussion over the answer is typically dominated by the person with the most status in the group (Chizik, 2001). In a variable-answer task: 
students may use many avenues to find the right answer. Discussion includes all members because they feel that they all have something to contribute (Chizik, 2001). Students must show a statistically significant change in their achievement due to group work and not because they silently work on the task while sitting in the same general area (Chizik, 2001)

Rewards are often given to students as part of the program. These can come in different forms. When mathematics groups are rewarded externally and individuals are held accountable for learning, student achievement increases in some cases, but in others it is not necessarily needed in others to ensure success (Davidson and Kroll, 1991; Fasko, 1994). Sometimes math problems and laboratories motivate students to succeed without externally rewarding the group (Davidson and Kroll, 1991). Self-efficacy, an internal reward, comes from when people are empowered to guarantee the success of their own learning (Griffin and Griffin, 1998). It does effect achievement positively (Griffin and Griffin, 1998).

Benefits:

According to several studies, students like working with a partner and will turn to him or her for advice before asking a teacher (Mevarich, 1985; C. Utay and J. Utay, 1997; Webb, 1991). This makes it easier for the teacher to give one-on-one help to those who needed it and lightened the demand for his attention (Chizik, 2001; Fasko, 1994). "We concentrate on peer mediation for two reasons. First we want to reduce the demands on teachers .... Second, prior research (Fuchs et. Al., 2000) suggest that dyadic rather 
than small -group structures may promote more intensive sessions and more productive interactions for students with disabilities and other low performing children” (Fuchs, Fuchs, and Karns, 2001, 3).

Cooperative learning is also simple, cost-effective way to help students with special needs (Fasko, 1994; C. Utay and J. Utay, 1997). More students are reached using the least money. This is because this method influences motivation, perserverance, and learning (Davidson and Kroll, 1991; C. Utay and J. Utay, 1997). For intermediate students of all levels of academic abilities, math partners have caused greater achievement in mathematics than traditional methods of instruction (Fuchs, 2001). “'Working in small groups increases each student's opportunity to interact with materials and with others students while learning. Students have more chances to speak in a small group than in a class discussion: and in that setting some students are more comfortable speculating, questioning, and explaining concepts in order to clarify their thinking'” (Webb, 1991). Students are not afraid to show their knowledge on a test, they feel better about themselves as students, and they excel academically (Griffin and Griffin, 1998). As a result, it leads to a more successful mainstreamed environment for learning disabled students (C. Utay and J. Utay, 1997). Students wanted to learn and were not afraid of failure. Low performing students benefit from this (Chizik, 2001).

Cooperative learning also helps average to above average students to grow in their ability to learn. Sometimes they make even greater strides than the students they tutor. (Fuchs, Fuchs, and Karns, 2001; Griffin and Griffin, 1998; Mevarich, 1985). Vygotsky 
states that language helps people by giving them a way to develop their ideas (Chizik, 2001). It is way for them to organize and reorganize their thoughts and academic knowledge (Chizik, 2001; Webb, 1991). Turning thought into language by discussing problems helps confirm concepts in the students’ minds (Chizik, 2001). It leads to a greater level of detail and therefore a greater level of learning in the group (Chizik, 2001). It also fosters social learning because they have to explain their thoughts and actions to each other (Chizik, 2001).

Peer tutoring increased self-esteem and attendance because students were motivated to give their attention to the task at hand (Chizik, 2001; Davidson and Kroll, 1991; Endsley, 1980; Griffin and Griffin, 1998; Mevarich, 1985; C. Utay and J. Utay, 1987). They love to socialize and learn at the same time (Davidson and Kroll, 1991; Slavin, 1987). Mevarich quotes a Johnson and Johnson study, which validates that cooperative learning leads to better racial relations and social skills (1985). Students are able to establish long term friendships that carried on beyond the time spent in a group setting, and they looked out for their partners welfare (Davidson and Kroll, 1991; C. Utay and J. Utay, 1997). Students discovered the importance of understanding each other's differences.

Behavior was improved as well because students are able to express their "needs in an acceptable way with out being either too passive or too aggressive” (C. Utay and J. Utay, 1997). Joseph Lancaster encouraged teachers to make the mischievous kids monitors (peer tutors) in the class (Endsley, 1980). When they take responsible for 
learning by thinking and understanding process of thinking, students are empowered to help others and improve their “academic and social skills” (Davidson and Kroll, 1991; C. Utay and J. Utay, 1997). Students who were taught these leadership skills expressed enjoyment of their new abilities (C. Utay and J. Utay, 1997).

Grouping:

Pairs are best for special needs students (Endsley, 1980). It was suggested that students with learning disabilities were paired with students who had no learning disability in the content area (C. Utay and J. Utay, 1997). Age does have an effect on tutoring (Endsley, 1980). Broader range in tutor/tutee relations leads to greater tutee cognitive performance (Endsley, 1980). However, if the students are the same age, pleasanter interactions happen and there are more positive feelings toward learning (Endsley, 1980). The lack of age difference can be compensated for by a difference in academic ability. The age difference has more to do with knowledge of the material than with maturity.

Research of cooperative learning within grade states the need to pair a high and a low ability student together (Fasko, 1994; Webb, 1991). “Chief among (the drawbacks of cooperative learning) is the lack of systematic feedback-corrective procedures. Teams, as performing units, may make an error and be unaware of it because they may not be supported with informative responses” (Mevarich, 1985, 372). A plan must be devised to check student work and allow them to redo any problems they figured incorrectly (Griffin and Griffin, 1998;Webb, 1991). Part of this problem can be avoided by always placing 
low level students with high level students (Webb, 1991). The result is the lower level student receives a deeper explanation by the high ability student. Average and low ability students did not work well together (Webb, 1991). In order to have a sufficient knowledge base, there needs to be a greater difference in academic ability (Webb, 1991). When pairing student of like ability, only two average students worked well together (Webb, 1991). Those with high abilities thought that their partner needed no help, and those with low ability were unable to give the necessary help (Webb, 1991).

Students know each other and have expectations of their classmates based on their classmate’s previous performance. A person's status within the group determines the level they will participate in the group (Chizik, 2001). Teachers must consider race, gender, student popularity, and math ability when grouping students (Chizik, 2001). Teachers can also gain insight by asking students who they would and would not like to work with and why (Chizik, 2001). In spite of careful pairing of students, one must still monitor groups. Webb warns that students who were more "extroverted" received more answers from their partners, and “introverted students” usually had their requests for answers ignored more than those who were outgoing (1991).

Status and significance play a role in the ability of people to work together; gender is one aspect that people use to establish the value of person (Chizik, 2001). For this reason, it is best to pair males with other males, and females with other females (Chizik, 2001). When establishing groups of four or more, there should be an equal number of each gender in the group to prevent the boys from dominating the attention 
and to give girls equal chance to excel (Webb, 1991). Chizik states that his study of high school English students shows initial expectations of ability or member status can be clouded by race or gender because of culturally ingrained bias (2001). Webb discovered in an above-average junior high mathematics study, boys requested help more, were rewarded with a response more often, and scored better on the standardized test than girls did (1991). On the other hand, gender made no difference in the behavior and academic performance of junior high students with low academic ability (Webb, 1991).

Mevarich believes that sex differences do not matter in academic achievement until high school according to her research (Mevarich, 1985). Mevarich’s project on $5^{\text {th }}$ grade math groups was confirmed in a second and third grade study Lindow, et al. from 1985. Webb uses this study in her analysis of gender to confirm that achievement is not affected by gender in elementary school (Webb, 1991).

Endsley lays out requirements of tutors. These include that they be literate and being able to borrow and carry. Both parties should be able to understand and follow simple directions. They need to have an attention span of at least 15 minutes. Tutors also should have no obvious cognitive disability that would affect the fulfillment of their duty (Endsley, 1980).

After choosing candidates for tutoring, be sensitive to student's behaviors as they begin the program (Endsley, 1980). Make sure they have the prerequisite skills necessary (Endsley, 1980; Griffin and Griffin, 1998). By ensuring everyone has something to 
contribute, no one is left out of the discussion because they lack knowledge or because they feel that others have higher status (Chizik, 2001; Griffin and Griffin, 1998).

Selection of tutees should also be based on learning needs (Endsley, 1980). Most of these students will have learning deficiencies (Endsley, 1980). They are the first to be considered when establishing partners (Endsley, 1980). However peer tutorial programs are not always for remediation purposes only (Endsley, 1980). The partner can be someone of equal academic standing (Endsley, 1980). Group work can challenge students by preparing them for later more complex materials (Endsley, 1980).

Program Structure:

Structured tutoring provides diagnosis of problem areas, planning to meet learning needs, motivation for low achievers, and methods for building skills while overcoming learning problems (Endsley, 1980; Webb, 1991). According to Chizik, task structure affects group dynamics, which affects achievement (2001). Task structure enhances participation. Participation benefits achievement when cooperation occurs within the group (Chizik, 2001).

Initial steps include preparing and pretesting the students. Each pretest should assess specific situations. They should begin with simple tasks or items and lead to more difficult ones in order to assess ability levels to define the entry point of an individual (Endsley, 1980). This could be a standardized test or one different form of the test used as the posttest. The pretest will help the supervisor to place the student (Endsley, 1980). 
Training is the key (Fasko, 1994). Fasko (1994) implemented a program where modeling and role-playing taught the tutors how to do their job. Before beginning, students were given instruction on how to run the program and work together as a team (C. Utay and J. Utay, 1997;Webb, 1991). The goal is that everyone learn the information and teams should be instructed to have every member do all of the problems (Webb, 1991).

Taking time to build relationships helps to reduce anxiety and builds the sense of community (Endsley, 1980). According to Mevarich, upper middle class students especially lack the skills and patience to work together (Mevarich, 1985). Students must also be taught that there are many skills required in completing the work and that everyone has something to learn (Chizik, 2001).

By recognizing student's strengths and teaching fellow students how to draw it out of them using questions, teachers set the groups up for success (Chizik, 2001) Training, monitoring and evaluating increases the likelihood of learning gains, positive attitudes in LD students, and higher academic development in peer tutors (Endsley, 1980).

Students need to be taught how to ask questions that get the help they need (Webb, 1991). Specified and controlled instruction on how to function as a group is vital 
because truly structured programs succeed while loosely arranged ones fail (Endsley, 1980).

Students must also be taught to explain how they got their answer during the time that they work together (Chizik, 2001). They are not just checking for the right answer, but also making sure that the proper steps were followed to get the answer (Chizik, 2001). Close monitoring (possibly video taping) can help the teacher understand the best methods for reaching students needs and to ensure that student tutors are not just giving the answers (Chizik, 2001).

Instead, the answers must be elaborated (Chizik, 2001). When they are explained, both parties learn in the process (Chizik, 2001). This was proven in the Webb study which found that students are encouraged to try harder when they are looked after, praised, corrected, and cheered on by their peers (Chizik, 2001; Webb, 1991). Students who are taught to continue to seek out the correct answer in situations like mastery learning excel academically more than those who do not (Mevarich, 1985). This must be a part of peer tutoring or students will continue on making the same mistakes without correcting them (Mevarich, 1985).

Groups experience different dynamics based on the type of task they are given. Students sought for clear correct answers according to the Webb study on single answer problems (Chizik, 2001). However, there tends to be more dominance and less discussion (Chizik, 2001). Males typically do better with single answer tasks, while 
women do better with discussions and variable answer tasks (Chizik, 2001). Caucasian do better on single answer group tasks than minorities do (Chizik, 2001). It affects the type of participation and is considered an achievement variable (Chizik, 2001).

When there is a variable answer, it creates task conditions ripe for equitable exchanges in participation according to Cohen’s study (Chizik, 2001). Prejudice diminishes when all interact in a non-superficial manner (Chizik, 2001). Students see each other for who they really are and they gain good skills by working together (Chizik, 2001). More conflict from variable answers leads to better conflict resolution if training is included in the task structure (Chizik, 2001).

Chizik felt that explanations in single-answer problems could help some; it also stopped learning in some cases (2001). Mevarich explains this as gains only in basic math skills like computation (1985). To succeed at more involved problems, students need to be a part of group discovery (Mevarich, 1985). Correcting errors in multi-step problems and single step problems leads to greater achievement on standardized math tests (Mevarich, 1985). Explanations helped learning in all variable-answer problems (Chizik, 2001).

Peer Tutoring is set up to encourage students to ask each other for help before asking the teacher. There is a high commitment to their partners in and outside of class resulting from a common goal (Fuchs, Fuchs, and Karns, 1994; C. Utay and J. Utay, 1997). This common goal must be learning for all within the group. "When the group’s 
task is to do something rather than to learn something, the participation of less able students may be seen as interference rather than help” (Slavin, 1987, 19). Student groups who work for a team prizes do not do as well academically as those who are motivated by the welfare of others (Mevarich, 1985). The program has succeeded when, as in the Utay study, students take pride in the accomplishments of others (1997). According to Carol and Joe Utay, there needs to be objective testing of sociometric and attitudinal changes to determine the level of success (1997).

\section{Group Work:}

Students work to achieve greater academic growth when they work with others in their class as long as they do so “constructively” (Fuchs, Fuchs, and Karns, 2001). However, one problem with cooperative learning is time “off task” (Webb, 1991). It hampers achievement whenever it "showed any consistent relationship with achievement” (Webb, 1991). Disruptive behaviors of the students can hinder the program unless they are dealt with by teaching the students to change (Endsley, 1980). Students that struggle academically tend to be "off task" more often than their more academically gifted peers are (Webb, 1991). Achievement depends on focused work.

Not only should behavior be monitored to prevent time from being wasted, teachers should also make sure constructive tutoring is being done. “ Research on students' behaviors within cooperative groups has consistently found that the students who gain most from cooperative work are those who give and receive elaborate explanations (Slavin, 1987, 19).” This elaboration should help the student master a new 
concept, understand the process of finding an answer, and fix incorrect answers (Fasko, 1994; Webb, 1991). However, the student must actually need the elaboration given, it must be understandable, it must be applicable, it must come at the right moment, the student must have a chance to use the information, and the student must choose to use it (Webb, 1991). Teachers need to understand how to make this happen. They have the power to shape the methods of learning, group dynamics, and content of the work over extended periods of time (C. Utay and J. Utay, 1997).

a. Explanation given only if person needs help. If the person has made a mistake, they need to be corrected (Fasko, 1994; Webb, 1991). If they need an explanation, they should receive one about a specific procedure (Webb, 1991). Though in some cases, students benefit from listening to others receive explanations (Webb, 1991).

b. Explanation must meet the need of the student. Tutor must figure out what the tutee understands and connect that to what is being taught (Webb, 1991). If success does not follow, “the explanation may not have focused appropriately on the receiver’s particular misunderstanding or lack of misunderstanding” (Webb, 1991, 373). Follow up must be done by attempting other methods of explaining the problem using other similar problems and defining difficult words (Webb, 1991). Students also need affirmation that they have done a problem correctly, but this does not improve their academic performance (Webb, 1991). Other times more detail is needed, and this leads to greater learning (Webb, 1991). Some students do not ask for a description of a certain problem solving process when they actually need it. Tutors need to be 
taught to be sensitive to the learner's need and to not just give the answer (Webb, 1991). Only then will success be experienced because in depth explanations of procedure leads to achievement (Webb, 1991). Just giving the answer or not giving enough help leads to academic failure (Webb, 1991).

c. Explanation comes on time. Because students working in the same group experience the same task and its complications, they know better than anyone else does what their teammates are lacking (Webb, 1991). They can explain it better than someone who approaches the problem from the outside (Webb, 1991). Timeliness means that students get help when they are in the middle of a struggle to understand a concept. Sometimes the academically strong students forget the needs of others and become focused on getting done quickly (Webb, 1991). If the struggling student does not get help when they need it, they may over look the problem and continue on in error (Webb, 1991).

d. Explanation is understandable. “(T) he receiver has to understand it, internalize it, and use it to correct the area of misunderstanding or lack of understanding” (Webb, 1991, 373). It should clarify the main ideas being taught in the classroom (Griffin and Griffin, 1998).

e. The learner has time to practice. Sometimes tutors do not give the person they are helping time to process their advice and use it. They want to follow behind and stop their fellow student from making another mistake. In the end, the student never gets a 
chance to finish the problem on their own (Webb, 1991). The tutor also does not know if the explanation was understood (Webb, 1991).

f. The learner uses time given to practice. It is always a choice for the student to ask for and accept help (Webb, 1991). The only thing that can be done is to attempt to understand why the person avoids asking for help (Webb, 1991).

g. It must be safe to ask for help (Webb, 1991). A moderate amount of "verbal disagreements” must be considered normal (Webb, 1991). Students need to be taught how to defend their answers (Webb, 1991). In the end, they will learn the material better than those who do not participate because they have had to explain their stance and look up new information to prove or disprove their answer (Webb, 1991).

As a whole cooperative learning may show improvement for the group, but some in the group may not understand certain concepts (Mevarich, 1985). The top students may be benefiting educationally, but there is no way to stop to let the lower students correct their faulty understanding (Mevarich, 1985). These students can be “'free rider'(s)” or 'sucker'(s)” who are not held accountable for their own learning (Webb, 1991). Following these guidelines for group discussion ensures the academic achievement of all.

A structured program is vital to the success of cooperative learning. Variables must be eliminated by careful grouping, training, and monitoring students (Webb, 1991). 


\section{METHOD}

The variables that may be encountered are the level of help provided and student cooperation with the each other in the group. The level of help provided will be modeled and monitored by the administrator. Student cooperation will be enhanced by team building activities at the start of the year.

In a school of 176 students, the fourth and fifth grade classes will be given the treatment. There are 23 fifth grade students and 14 fourth grade students. A pretest will begin prior to the first lesson. After the completion of the section by the groups, a posttest will be given. The test consists of 20 computation and problem solving questions. The scores of the two will be compared and charted. This will continue for the first 12 weeks of school and thus produce 6 sets of test results for each grade. At the end of the study, the achievement scores of the past year will be compared with the results of this year. Any differences will be noted and considered as the results of the study are assessed.

The source of the data is a small private school located in a rural community. The families are middle to upper class. Many of the parents work in factories and professional offices. A few parents farm. Both fourth and fifth grade classes are given the treatment. Students in both grades will be grouped according to their mathematic achievement during the previous year. 
Numerical data will be collected from the math tests given at the beginning and end of each unit. The company that published the math textbook used in this study prepared the tests. The publisher provides an A and B version for every test. These will serve as the pre and posttests. Stability continues to be evident throughout the year as the level of difficulty in the curriculum increases. Achievement tests given every year will provide the comparative data needed to show grade equivalent progress in mathematics.

Data analysis has shown that there was a significant improvement on the part of the students in some cases. However, the results were inconsistent. Some of the curriculum-based tests showed improvement between pre and posttests while others did not. This was also true of the standardized test scores. The fourth grade students improved significantly while the fifth grade showed no significant correlation between group work and academic achievement. We will discuss further in the result sections the underlying reasons for such skewed results.

The final results show that peer tutoring has enhanced some students’ abilities to succeed at math in certain cases. Achievement test scores and math grades are quantitative proof to that end. 


\section{Chapter II: Literature Review}

\section{Benefits:}

Tutoring is the perfect setting for learning because is an economical way to ensure students get an academic boost (Roach, Paolucci-Whitcomb, Meyers, \& Duncan, 1983). It increases student social skills, self-esteem, drive to accomplish school work, desire to be a part of school, academic success, good actions, and standing with peers (Jacques, Wilton, \& Townsend, 1998; Roach et al., 1983). Collins and Onwuegbuzie noted that while a significant amount of students did better after participating in a tutorial program, that they did not increase their achievement in mathematics as they had in other subject areas (2001). These researchers believed that there may be a need to adjust pedagogical methods to promote further success in understanding the material presented (Collins \&Onwuegbuzie 2001).

When the teacher establishes a well-planned program where blocks to success are removed, students make great academic progress using cooperative learning (Roach et al., 1983; Madden et al., 1997). They are in control of their own academic growth which prepares them to be "strategic, flexible, self-aware, and motivated problem solvers in mathematics (Madden et al., 1997). These students see improvements in their achievement test scores (Madden et al., 1997) and drive to succeed (Nichols \& Miller, 1994). 
Their enjoyment of gaining knowledge leads them to be more persistent, have a higher view of their ability to succeed, and be more likely to strive to achieve than those who work alone (Nichols \& Miller, 1994; Yamaguchi, 2003). "Students in the cooperative learning classroom exhibited significantly greater gains in achievement than the control group in algebra achievement, efficacy, intrinsic valuing of algebra, and learning goal orientation” (Nichol \& Miller, 1994, p. 167). Pinzker saw a growth in passing grades, understanding of the mathematics, and positive feelings about the ability to achieve success in learning mathematics (2001). However, as in the Nichol and Miller study, we may see a regression of positive attitude and academic success when students are no longer permitted to work in cooperative groups (1994). Yamaguchi also found that groups more focused on individual achievement and task accomplishment lead to self-centered behavior and fighting rather than the benefits of a team approach (2003).

Studies on cooperative learning prove the adage that doing something to increase the academic success of a child is better than doing nothing (Wong, Jawson, \& Keeves, 2002; Leighton, Slavin, \& Davidson, 1989). However, the fact that some things work better than others must also be considered (Hoek, van den Eeden, \& Terwel, 1999). These include group rewards, personal achievement testing, and equality for all (Slavin, 1996; Madden et al., 1997).

In Roach et al's (1983) study also, the peer tutoring teams did better on their achievement testing than those not participating in the tutoring program. Students in the peer tutoring had a stronger grasp on the subject matter than students not participating 
(Roach et al., 1983). The greatest achievement in the pre and post test came from the peer tutoring group (Roach et al., 1983). This shows that peer tutoring positively effects achievement in the classroom (Roach et al., 1983). Researchers can take this knowledge and use wisdom gained from program techniques to establish methods of good communication in group work (Wilczenski et al., 1999; Wolford et al., 2001).

The question of the significance of the elaboration technique was answered in that students who had experience elaboration in their groups did significantly better than their counterparts on the more difficult questions of the exam (Wong et al, 2002; Gillies \& Ashman, 1996; Leighton et al., 1989). Questioning helps students somewhat when it comes to working toward greater understanding of a text or problem (Wong et al, 2002). This includes “comprehension, connection, strategic, and reflection questions” (Kramarski et al. 231, 2002). “(C) omprehension questions” help the student define what the problem is and ensure that they fully understand (Kramarski et al. 231, 2002). " (C) onnection questions” enable the student compare their current problem with a previous one (Kramarski et al. 231, 2002). “(S) trategic questions” involve discussing an appropriate way to solve the problem and the reasoning behind it (Kramarski et al. 231, 2002). “(R) eflection questions require processing and of the student’s understanding and feelings (Kramarski et al. 231, 2002). Understanding: Hiebert (1986)” The process of creating relationships between pieces of knowledge. Students understand something as they recognize how it relates to other things they already know.” (p.21) (Gutstein \& Mack, 1999, 441). Metacognition involves understanding and managing “one’s thinking and learning activities” (Kramarski, Mevarech, \& Arami 227, 2002). This process varies 
with age and academic subject, and students must be taught to begin using this method as they work on math problem (Kramarski et al., 2002).

Students did better on mathematics "objective” standardized testing when their inclass assessment came in the form of an essay test (McMillan, 9, 2003). Processing what the student learns is far more important, and therefore questions must lead to this greater digestion of the information (Wong et al, 2002; Gillies \& Ashman, 1996). Elaboration improves the level of cognitive connections (McMillan, 2003; Wong et al, 2002). The question of how elaboration affected the quality of the discussion and the ability to solve the problem was answered in that student were able to arrive at descriptions of their thought processes while making conclusions about the more difficult problems (Wong et al, 2002; Leighton et al., 1989). It is in these types of posttest problems that students who elaborated showed their greatest achievement above their counterparts who were not required explain their position in depth (Wong et al, 2002). Wong et al. proposes that more time needs to be spent on discovering how the mental filing process works and methods of strengthening it (Wong et al, 2002). This redefining the student's understanding and reasoning through new avenues of knowledge is an on going process (Wong et al, 2002).

Elaboration of thought process showed significant gains intellectually when it is done (Wong et al, 2002). The question of what level of control elaboration has over a student who analyzes his own understanding was answered in that typically students who spent time in elaboration of their thoughts also analyzed their level of comprehension 
(Wong et al, 2002). The more time they spent on both activities correlated with their level of effectiveness as a student (Kramarski et al., 2002; Wong et al, 2002).

Not only did their personal achievements grow, but also their effectiveness in relating to their fellow students improved. Jacques et al. (1998) states that students with slight learning disabilities were more accepted by their peers when cooperative learning was used. Though their peers expressed initial fear about interacting with the disabled students, they became more confident as they learned appropriate responses to their partner (Clemenz, 2002). The understanding they developed helped them learn to discern stereotypes, protect "privacy" and value the other person (Clemenz, 22, 2002). Teams that were given instruction on how to work together ended up working better together, were more willing to care for the needs of their teammates, made others feel more apart based on what they said, and offered more elaboration to their teammates (Gillies \& Ashman, 1996; Jacques et al., 1998; Kramarski et al., 2002; Yackel et al., 1991). Trained teams produced more independent learners that achieved far more than their untrained counterparts (Gillies \& Ashman, 1996; Kramarski et al., 2002; Yackel et al., 1991). They were not so focused on themselves, but desired to accomplish the group task through “problem solving”, “consensus seeking”, and "genuine attempts to communicate” (Yackel et al. 401, 1991). They were more supportive of their fellow teammates (Clemenz, 2002).

They also focused on the process of problem solving instead of the external aspects of the problems (Kramarski et al., 2002). Students that excel at problem solving 
consider all of the information given to solve the problems and build their own algorithm instead of searching for key words to define which pre-established algorithm to use to solve the problem (Kramarski et al., 2002). The questions taught to the problem solvers led them to look at all angles of the problem, consider many possible ways to answer the problem, and be prepared to explain their method (Kramarski et al., 2002). Trained students are better able to explain the reasoning behind the mathematical choice they made and take control of their education process (Kramarski et al., 2002). As confidence is built, there is less of a chance that students who are right back down to those who are wrong who have stronger personalities than them. This may also give them new belief in their capabilities to attempt new things (Kramarski et al., 2002). Lower level students progressed even more in these abilities than higher level students as their ability to make connections with past and present knowledge increased (Kramarski et al., 2002).

Rewards for practicing together, testing separately really work better than systems that lack incentive or individual responsibility (Slavin, 1996; Leighton et al., 1989; Madden et al., 1997). Group incentives with “individual accountability” do not inhibit the achievement of students in the long run when learning lower level skills and students actually prefer this over the traditional concept of competition (Slavin, 1996; Leighton et al., 1989; Madden et al., 1997). All students can reach success as long as they reach the level of proficiency (Madden et al, 1997). When children realize that their ability to obtain rewards is based on their fellow group member's progress, they will be more willing to encourage and explain the concept to their teammates (Nichols \& Miller 1994). Studies actually show stunted growth in certain cases without rewards (Slavin, 1996). 
However, some studies have shown that students can be challenged to elaborate and reason through deeper levels of relevant material as a team without the reward (Kramarski, Mevarich, \& Arami, 2002; Slavin, 1996; Yackel, Cobb, \& Wood, 1991). In Wong et al. (2002), the group of students that elaborated earned a better score than those who did not elaborate. However, researchers are finding more frequently that rewards and patterned interaction are necessary (Slavin, 1996; Yackel, et al., 1991).

Using past, present and future, students can be helped to grow in their understanding of mathematical concepts (Gutstein \& Mack, 1999). By considering past mathematical knowledge, the tutor can help remind students of what they have learned, help them to understand, and enable them to correct any misconceptions (Gutstein \& Mack, 1999; Madden, Slavin, \& Simmons, 1997). It establishes a foundation for the present and the future (Gutstein \& Mack, 1999).

When establishing the foundation, immediate intervention is vital to the persistence and eventual success of each student. When fellow students respond to the questions about their area of struggle right away with a detailed answer, students develop a much stronger understanding of the problem; they succeed because of the additional practice they are able to accomplish (Abrami \& Chambers, 1996). This produces a setting where interpersonal needs are met (Abrami \& Chamber, 1996; Jacques et al., 1998). "Interpersonal motives encourage learning together through peer support (e.g., help receiving), and prosocial tendencies (e.g., help giving), and affiliative need (e.g., belonging)” (Abrami \& Chambers, 1996). 
On the other hand, if students do not work well with their teammates, this can negatively affect their ability to adapt and interact with others thus coloring their beliefs about their ability to succeed (Abrami \& Chambers, 1996; Jacques et al., 1998; Wilczenski et al., 1999). They believe they cannot change their pattern of success even with an intervention or change of program (Abrami \& Chambers, 1996). Intervention and training are necessary to prevent any detrimental effects of cooperative learning. As Slavin states, teaching students to work together and process after the activity leads to greater academic growth (1996).

In addition, group members encourage others to succeed because they need the rest of the group to do well individually in order to receive a reward (Abrami \& Chambers, 1996; Slavin, 1996; Madden et al., 1997). 78\% of studies that provided rewards for working together successfully while being held accountable separately showed growth in achievement (Slavin, 1996). The lack of vying for position leads students to build each other up in the learning process and to do their best to meet the requirements (Slavin, 1996). According to Slavin, this is necessary when the groups are not voluntary, all members are required to complete the task, and the group is searching for specific answers to each problem (Abrami \& Chambers, 1996). Various methods of motivation are needed in these cases to encourage students to follow the program structure and pattern of dialogue to ensure the success of the cooperative group. Rewarding improvement leads to challenging each other to do better (Slavin, 1996). 


\section{Program Structure:}

In establishing a program, Slavin (1996; Madden et al., 1997) suggests the first 15 minutes be “Check in” where teams complete a relevant problem. The next 40 minutes the teams spend working on learning, checking, and practicing the concept of the day together (Slavin, 1996; Madden et al., 1997). The last five minutes is for "Reflection” when the teacher sums up the main ideas of the day (Slavin, 1996; Madden et al, 1997).

To monitor achievement in a study, pretest and posttests are given at the beginning and end the study (Kramarski et al., 2002; Roach et al., 1983). During this time monitoring is in place to ensure no cheating occurs and to help students in reading the problem (Fuchs et al., 2002). If students were not pleased with their posttest score, they were permitted to take an equivalent form of the posttest (Nichols \& Miller 1994). This opportunity apart from cooperative learning has been found to increase the students' confidence and desire to set benchmarks to achieve (Nichols \& Miller 1994). In the end, groups of students should be rewarded based on increase in progress rather than achievement (Nichol \& Miller, 1994).

Methods of motivation and task structure shape the effectiveness of cooperative learning (Slavin, 1996) because tutoring is a multifaceted task (Gutstein \& Mack, 1999). Teaching involves both the tutor understanding of the material being covered and the tutee’s abilities and response to the help given (Gutstein \& Mack, 1999). It is an experience in which the tutee is guided through a series of questions to help them process math knowledge (Gutstein \& Mack, 1999). In the process, the tutee is called to change 
beliefs and methods of action (Huber, 2003). Cooperative learning may aid or destroy the achievement of this goal depending on the individual's “orientation” (Huber, 2003, p. 258). The true question is whether or not they can handle having to search for the answer in a verbal malaise rather than being told directly what is right (Huber, 2003).

Training is vital to ensure that the tutoring is actual beneficial (Gutstein \& Mack, 1999; Hoek et al., 1999; Wolford, Heward, \& Alber, 2001; Yackel et al., 1991). Researchers prove the importance of teaching students methods in figuring story algorithms, the amount of instruction necessary, and what exactly makes it possible for the student to understand the underlying concept being discussed in problem solving (Fuchs et al., 2002; Hoek et al., 1999). The success of the small group will prevent one frustrated student from doing all of the work or giving answers to the other person without ensuring understanding (Slavin, 1996; Wilczenski et al., 1999). It will also help to calm the stress of the "certainty-oriented students" (Huber, 2003, p. 259). Modeling can help make this possible (Gutstein \& Mack, 1999) and to prevent misunderstanding and wasting time (Abrami \& Chambers, 1996; Hoek et al., 1999). “More capable peers provide stepping stones or scaffolds in the development of other students' thinking” (Abrami \& Chambers, 1996). They break the problem solving process down into smaller pieces, and emphasize the importance of the correct or the numbers of answers (Abrami \& Chambers, 1996; Slavin, 1996; Fuchs et al., 2002). Leighton et al. (1989) quotes Polya's suggestion for a four part plan that involves comprehending the problem (Swann’s original problem), making up a plan of attack (Swann’s attempt to solve the problem), accomplishing the plan (Swann's eradicating the problem), and reflecting 
(Swann's realization of a new crisis) (Kramarski et al., 2002; Leighton, 1989; Swann, 1999; Yackel et al., 1991). Training in verbalization is key to ensure success and check understanding (Kramarski et al., 2002; Hoek et al., 1999; Wolford et al., 2001; Wong et al., 2002). Swann believes that learning this skill happens when a person realizes a problem, tries to fix it, and is not killed in the process (Swann, 1999).

Learning for humans is often not realized because it is unplanned, unorganized, and imbedded in the situation (Swann, 1999). Even if the unexpected is welcomed, there is still an aspect of discomfort (Swann, 1999). Some people learn best from attempting the whole project over and over (Swann 1999). The refinement process which may take several attempts leads to change in the person and the environment (Swann, 1999).

“Collaborative learning is defined as students working together, without immediate teacher supervision, in a group small enough so that everyone can collectively participate on a task” (Wilczenski et al., Bontrager, Ventrone, \& Correia 1999). Cooperative learning must have certain parameters to ensure success (Slavin, 1996). Everyone in the group participate in the solution by using each other's prior knowledge to gain new insights not previously obtained before working together (Wilczenski et al. et al., 1999; Hoek, van den Eeden, \& Terwel, 1999; Leighton, Slavin, \& Davidson, 1989). Cooperative learning success is defined by the accomplishment of the group, students' ability to perform individually, and student's ability to be a contributing member of their group (Wilczenski et al. et al., 1999; Leighton, et al., 1989). Slavin promotes using a 
"project-based" approach to group work so that it is more specialized for each group and practical (Grossen, 1996). The work is set up in a way that requires the children to explain their knowledge of a certain subject to other students (Abrami \& Chambers, 1996; Slavin, 1996; Madden et al., 1997). Their prior knowledge had a substantial effect on their ability (Kramarski et al. 231, 2002). They come together and use this knowledge through a process called collaboration in an attempt to reach students who struggle (Kramarski et al. 231, 2002).

This requires reteaching or modification if some of the group members do not understand (Grossen, 1996; Madden et al., 1997; Yackel, Cobb, \& Wood, 1991). By mixing achievement groups and teaching to the higher level students, teachers and tutors can do just as much damage as if they were placing those students in a substandard classroom to do worksheets all day (Grossen, 1996; Wolford et al., 2001). Students must be given a chance to learn at their own pace things that are taught to them on their own level by their teammates (Grossen, 1996; Wolford et al., 2001). Students should not be demanded to out perform their ability (Grossen, 1996). However, equality and stellar level of education are requirement to ensure that lower level students are maximizing their learning potential (Grossen, 1996).

Looking to the tutee to understand what they need in the way of practice and challenging them to think on a deeper level as they complete their work leads to longer lasting progress (Gillies \& Ashman, 1996; Slavin, 1996; Wood \& Wood, 1996). These students are more independent and can interact with the knowledge on a higher plane 
because they are good at making connections (Gillies \& Ashman, 1996; Kramarski et al., 2002; Wood \& Wood, 1996). Typically, the successful students do this automatically. However, for the lower level students, the structure must be established (Wood \& Wood, 1996; Fuchs et al, 2002; Hoek et al., 1999). Peer tutors produce the bridge to help their fellow students reach higher levels of reasoning (Abrami \& Chambers, 1996; Wilczenski, 1999). Students with math disabilities need help learning how to structure their problem solving, defining the ruling principle behind how a problem is answered, and analyzing new problems in light of their past experience (Fuchs et al., 2002; Hoek et al., 1999; Wilczenski et al., 1999; Kramarski et al., 2002). In order to do this, students need to have a grid which they use to define what kind of methods will help them solve certain problems (Fuchs et al., 2002). Tutors are working towards enabling students to use a few grids to analyze all problems (Fuchs et al., 2002). This is done effectively by prompting students to recognized principles in problems that define how they are solved through “mindful abstraction” (Fuchs et al., 2002).

Students also need to understand how to successfully work together in a practical manner that meets all learning styles (Garthe, Poremba, Schmidt \& Summers, 1998). Tips like talking quietly, good manners, sticking together, looking for help from your group, building up each other, sympathizing with others, and good listening skills can be initially taught by lecture and then practiced and re-taught in other ways like discussion, modeling, and play-acting (Beetham, McLennan, \& Witucke, 1998; Garthe et al., 1998). Taking time to analyze their success will cause students to understand what has happened in their group and how to better work together including compromising (Beetham et al., 
1998). Garthe et al. suggests that there be reinforcement throughout the week of the weekly lecture on social behavior (1998). Students need to learn "positive interdependence, face to face interaction, individual accountability, interpersonal and small group skills, and group processing skills” (Beetham et al., 1998, p.34-35).

Students do not naturally know how to succeed at "active listening and summarizing, giving and receiving explanations, and elaborating verbal responses” (Beetham et al., 1998, p.35). They have to be taught "communication, trust and decisionmaking” (Beetham et al., 1998, p.35). Those who are prepared to succeed feel their teammates value and understand their suggestions, are more willing to accept others input, believe their presence impacted the ultimate conclusion made by the group, and are happy with the end result (Huber, 2003). Students need to feel that they are a valuable part of the solution (Garthe et al, 1998). Expressing gratefulness, acknowledging wrong, avoiding bad influences, and setting a good course in life are produced when students are provided with a pattern (Beetham et al., 1998). Studies shows that the frequency of poor behavior dropped as students were trained in working with people (Beetham et al., 1998; Garthe et al., 1998).

No matter how we plan, problems will occur in discussion. They can be positive or negative additions to the learning process. A "problem refers to any situation in which an individual experiences a feeling of physical mental, or psychological discomfort (sense of disequilibrium or a awareness of dissonance) and where the individual desires to regain equilibrium” (Swann 261-262, 1999). Interpersonal relations or the students' 
approach to class activities can spark a problem (Yackel et al., 1991). A problem occurs when this feeling of "discomfort" is as a result of differing opinions (Swann 262, 1999; Yackel; 1991). That feeling is what drives the desire for resolution and learning (Yackel et al., 1991). These conflicts should be simply recognized as real life current issues or fabricated problems that will enhance the students' ability to deal with situations that come up in the future (Swann, 1999; Yackel et al., 1991). Conflict should be seen as an opportunity to grow.

Math problems that are considered "authentic" are ones that give students information about a situation with which they are familiar; the students are then given the task of figuring out how to solve it since there is no set pattern given to them (Kramarski et al., 2002). These problems have many different angles to approach the problem and the information is believable increasing the relevance to the student (Kramarski et al., 2002). These problems require a wide variety of math skills to accomplish the task (Kramarski et al., 2002). However, they are not often used because they take much time to accomplish, and the process to figure them out is unpredictable (Kramarski et al., 2002).

Unfortunately, sometimes these problems do not spur on learning. There are several reasons why the conflict in problem solving is not productive. If it is not acknowledged and the student does not want to see change, then the uncomfortable situation is not considered a true problem demanding a solution (Swann, 1999). If the problem does not apply to the student's life, it is not authentic (Yackel et al., 1991), and it 
has little impact. No matter the situation, the student must have to desire to learn and be looking for changes in his life that exhibit learning for problem solving to occur (Swann, 1999).

Heuristic methods of teaching help "learning, discovery, or problem solving by experimental and especially trial-and-error methods; of or relating to exploratory problem-solving techniques that utilize self-educating techniques (as the evaluation of feedback) to improve performance (Merriam-Webster on line dictionary http:// 63.240.197.92/cgi-bin/mwdictaj). Along that same line, "Mindful Abstraction" is the ability to recognize a pattern in new situations by stripping away the excessive details of the problem (Fuchs, Fuchs, Hamlett, \& Appleton, 2002). It is finding the solution to the problem by realizing the actual goal attempting to be reached and closing the conceptual gap between past experience recognizing solutions and present problem. (Fuchs et al., 2002). Sometimes this involves considering abstractions that have been used in the past (Fuchs et al., 2002). In the process, mistakes must be found and plans must change so that learning can happen more quickly (Swann, 1999). Discovery learning like this in a group before the grade is taken is a safe place to discover wrong answers or faulty reasoning (Swann, 1999).

In problem solving, one concern is that students who normally do well in mathematics might struggle with the idea of problem solving because there are no clear cut patterns for solving the problems (Kramarski et al., 2002). These students have to discover that on their own (Kramarski et al., 2002). They might also struggle to make 
connections between prior knowledge and the current problem (Kramarski et al., 2002). Specific tutoring strengthens the ability of LD math students to succeed to a greater extent at figuring solutions to story problems (Fuchs et al., 2002) or at social interaction (Jacques et al., 1998).

In problem solving, another concern is that the conclusions reached are not always accurate. Sometimes students think they are wrong when they are actually correct (Swann, 1999). Students may also learn incorrect information because of pressure to conform from the group, or they may struggle grasping what is really true (Swann, 1999).

A third concern faced in problem solving is change. This may be difficult because students are not used to working in groups. Their expectations are different than reality. Everyone initiates an activity with ideas of what will happen (Swann, 1999). People look for a patternable sense of normality or a connection to their prior knowledge; it is missed when it does not occur (Swann, 1999). When normalcy is missing, the expectation is challenged and must be changed (Swann, 1999). It is at this time that the student must carefully consider the input of others about going further down the cognitive path on which his group began (Yackel et al., 1991). Students and the instructor have roles to fulfill (Yackel et al., 1991). If the teacher can establish those basic expectations at the beginning, students will assimilate much more easily (Yackel et al., 1991).

For example, students with math learning disabilities in Fuchs et al. (2002) study also had a learning disability in reading (Kramarski, Mevarech, \& Arami, 2002). This 
difficulty required modification on the part of the teacher, and separation had to be made between a reading skill and a problem solving skill (Fuchs et al., 2002; Kramarski et al., 2002). In other situations like this, the instructor can change the obligation of team members if it would help the team achieve results (Yackel et al., 1991).

In another example, students that struggled in math had trouble figuring and checking their work (Kramarski et al., 2002). They also had trouble reordering the data (Kramarski et al., 2002). Therefore, it was a matter of reaching out to others and balancing in group work to ensure the group established healthy pairs that contributed to the welfare of each other (Yackel et al., 1991).

One of NCTM's goals is to do just that. NCTM's focus is to instruct students to appreciate math, to believe in themselves cognitively, to reach proficiency as mathematical critical thinking, and to interact in the realm of mathematics (Hong, 1996). They have established standards that are similar to the ones set up by the states (Madden, Slavin, Simmons, 1997). Students should be prepared emotionally and functionally to perform mathematics (Hong, 1996). To do this, NCTM encourages practical, discovery learning instead of using figuring random "algorithms"; logical problems are solved instead of completion of a long list of math problems (Slavin, 1996; Leighton, Slavin, \& Davidson, 1989; Madden et al., 1997). The goal is to have student move from the concrete to the symbolic (Slavin, 1996; Madden et al., 1997). When this occurs the concrete helps can be gradually removed or added back to the process as contingent aids 
if need be (Madden et al., 1997) In learning to think critically, students "clarify, extend and refine” their knowledge (Slavin, 1996; Madden et al., 1997).

To be able to appropriately analyze problems, students must be able to count on standard algorithms to be used in there particular grade (Fuchs et al. 2002). They then can compare the new problem to these grids and decide which one is most fitting (Fuchs et al. 2002). The students need to be taught to not necessarily look at the outward appearance of problems but instead consider the mathematical strands that are being dealt with in each problem (Fuchs et al., 2002). Outward difference in problems makes recognizing problems possible; however, knowledge of recognizing problems is simpler when you recognize by concept (Fuchs et al., 2002). Teachers need to express an established pattern to their class teaching a method of extracting the way the problem should be solved (Fuchs et al., 2002). Fuchs et al. used a more outwardly apparent method of discovering the concept in the problem when they set up their study (Fuchs et al., 2002).

Students need to be gradually eased into applying a pattern to new problems (Fuchs et al., 2002). Starting with a small range of problems, student eventually are able to decipher the pattern easily (Fuchs et al., 2002). This can be accomplished by showing the same problem written in different ways (Fuchs et al., 2002). Students were eventually given problems that were different in their underlying story and outward appearance (Fuchs et al., 2002; Wong et al., 2002). Students were also held accountable to complete deciphering tasks on their own as they worked to complete achievement tests 
(Fuchs et al., 2002). This is where a great difference is shown in the students who worked in groups where elaboration occurred and those who did not (Wong et al, 2002). Elaboration becomes a habit and pays off when students are faced with new situations where they must work to understand completely new problems (Wong et al, 2002).

Another concern Wilczenski et al. (1999) found that students working together received better team and personal scores for figuring correct answers. They then assess each others knowledge of the material (Slavin, 1996). When students each do their share of the work, they establish a positive, motivational environment (Abrami \& Chambers, 1996; Slavin, 1996). The rewards for achievement produced by all students including those less able ignites excitement in the group and they are more willing to take responsibility for producing a good learning environment by elaborating (Slavin, 1996; Gillies and Ashman, 1996). Not all students of the same age should be expected to perform at the same level (Grossen, 1996). Expectations for student performance should vary (Grossen, 1996). Teachers should freely discuss with parent and child, their perceptions of the child's ability and performance level to avoid misconceptions (Grossen, 1996). Praise should be given when students reach or exceed the “expectation” (Yackel et al. 394, 1991).

In order for students to reach that learning goal, clear instruction is required (Fuchs et al., 2002; Hoek et al., 1999). Students need to be helped by clearly teaching the method, using many problems already completed, hands on activities, and practice with peers (Fuchs et al., 2002; Hoek et al., 1999). Hoek et al. (1999) suggests a problem 
solving model be established and taught to the students. Students also need to be taught social skills; this runs hand in hand with the teaching of problem solving skills (Hoek et al., 1999; Jacques et al., 1998). Both training in how to work together and in thought process skills have been proven to help the more specific content and reasoning abilities of the students (Hoek et al., 1999). Students are taught and shown how to work the problems, (Fuchs et al., 2002). They are introduced to the concept by real life example that they can relate to (Fuchs et al., 2002).

Visual methods can be used to promote this type of problem solving and can act as a scaffold to help the students reach their potential. Posters of the patterns of problem solving and ways to solve them are posted in the room as a guideline for defining the problems’ pattern (Fuchs et al., 2002). Students worked in pairs to complete answers that are checked so that they can adjust their faulty reasoning in problems solving (Fuchs et al., 2002; Wolford et al., 2001). Finally students are asked to do some problems on their own (Fuchs et al., 2002). Showing novices how to figure problems and giving them opportunities to do the problems help ensure, but are not the defining factors in the success of all students (Fuchs et al., 2002; Pratt \& Savoy-Levine, 1998). Help is scaffolded as students work for greater periods of time at answering problems on their own (Fuchs et al., 2002; Pratt \& Savoy-Levine, 1998; Hoek et al., 1999). Teaching students to gradually ask for help less and work longer on their own may help them be less annoying to the students who give them feedback (Wolford et al., 2001) and helps them to become more independent learners. 
“A good teacher coaches the students during their attempts at problem solving by posing such questions as: What (exactly) are you doing? Can you describe it carefully? Why are you doing it? How does it fit in with your solution? How does it help you? What will you do with the solutions you get?” (Hoek et al., 1999).

In this same manner, teaching students to work in cooperative learning groups should be done in a direct, overt way that prepares them for their work situation while they are working, involve activities in the same content area as the objective, and help the students function at a higher level of cognition (Hoek et al., 1999). Students should be taught to use basic frameworks to solve math problems, be able to choose the correct strategy and use it when it is fitting (Hoek et al., 1999).

Interaction socially is also an important aspect of cooperative learning (Hoek et al., 1999; Gillies \& Ashman, 1996; Jacques et al., 1998). Everyone should be involved in the process of learning by contributing from their area of strength during the group discussion (Hoek et al., 1999; Gillies \& Ashman, 1996). The key to success is in understanding how successful students arrive at their learning level (Hoek et al., 1999) and how to foster social skills in students that lack the ability to work well with others (Zukauskas, 1998).

Students’ ability to work well with others is frequently affected by multiple factors. For example, the type of work being done and the way the group processes the information leads to different learning reactions (Wood \& Wood, 1996; Akhras \& Self, 
2002). “Authoritative” style of leadership tends to produce better problem solvers than people who are "nonauthoritative" and either try to control or tend not to have the structure that the child needs (Wood \& Wood, 1996). In cooperative learning, the tendency is for higher level students take control of the group and to give the answers to those who struggle (Wilczenski et al., 1999). This is evidenced in Wilczenski et al. study by the high level of input on the part of more academically gifted students (Wilczenski et al., 1999). They may not permit questions, minimize the input of lessable students, and keep them from learning through processing knowledge (Wilczenski et al., 1999; Wolford et al, 2001). This is where group incentives and individual accountability are important (Slavin, 1996). They motivate students to submit to the norms of group communication established by the teacher (Wilczenski et al., 1999). If everyone in the group does not do well, the team loses a reward (Gillies \& Ashman, 1996). This external motivation keeps the power of the higher level student in check and promotes a more authoritative, inclusive approach to team work. The higher level students must be discouraged from authoritarian methods of working with others so that more learning can occur (Swann, 1999). Students learn more when they are an active participant in the discovery of the answer and not just told what they should know (Pratt \& Savoy-Levine, 1998).

As a result, the grades show what has been learned by the individual. Studies show that teachers hope that the grades they assign students will accurately represent the work that the child expended and his progress while encouraging them to try harder (McMillan, Myran, \& Workman, 2002). Teachers feel they should be given based on 
the work done by the students (McMillan, et al. 2002; Yackel et. al, 1991). They also want to be sensitive to the amount of expectation they put on students to perform; many use things other than tests to grade the children (McMillan, et al. 2002). They consider ability because they do not want to discourage students' efforts (McMillan, et al. 2002).

However, consistency in grading is also important (McMillan, et al. 2002). There is a difference in grading usually because teachers use their perspective on education and what they feel is best for children to define their method of grading (McMillan, et al. 2002). However, there is a problem when students and their parents are mistakenly given the impression that the students have achieved mastery when they have not (McMillan, et al. 2002). This occurs when they lack knowledge and skills yet are rewarded for trying (McMillan, et al. 2002). This is part of the problem with Stuart's attempts at group grading (Stuart, 1995).

The other problem was her attempt to shape unity when the less able students' grade brought down the grade of the higher level students (Stuart, 1995). In her results you can see the response of some of the students was negative for this reason (Stuart, 1995). Just like the Grossen (1996) study said about the method of teaching students, if it does not raise the level of achievement, it is not a good method.

\section{Motivation:}

Motivation is an important part of raising the level of achievement. Enjoyment of work is vital to persevering in spite of boredom (Sansone, Wiebe, \& Morgan, 1999). 
When students are given the freedom to invent their own method of working toward a solution, they and their tutors often learn from the experience (Wood and Wood, 1996; Slavin, 1996; Madden et al., 1997). Producing solutions stretch the mind and is a form of "discovery learning” (Slavin, 1996, 50). This is the challenge for higher level students who may be used to having the algorithm handed to them and then having to apply it (Kramarski et al., 2002). They have to learn to create a connection between their past experience and the current real life problem being faced (Kramarski, et al. 2002). When students understand the context of the mathematical problem, they will more likely succeed in solving it (Hong, 1996).

Purpose in the work is vital to the students' willingness to continue even when the work produces a sense of boredom (Sansone et al., 1999). Students either need to understand the positive effects of the task, be able to make the task interesting, be committed to finish, or have the internal strength to tough out the difficult experience (Sansone et al., 1999; Slavin, 1996; Fuchs et al., 2002; Hong, 1996). This is key for working with students who have special needs in mathematics and motivating the higher level students to help the less able students. It will encourage the struggling student to keep trying and the higher level student to be more patient.

Encouragement throughout the process is helpful. If students feel that there is no reason to continue, they become restless or exhausted; it may be because they do not vary the procedure according to Sansone et al. (1999). Boredom leads to stagnation. However when a student feels an intrinsic desire to complete a task, they will volunteer 
readily to do so and learn more no matter what difficulty they face (Hong, 1996; Gillies and Ashman, 1996; Madden et al., 1997).

Willingness to commit to doing what is best and a desire to improve their own attitude toward their project also affects the students' stamina which is vital to finishing the task (Sansone et al., 1999). Slavin found people who had good feeling about working in cooperative groups usually did better in cooperative teams than others who felt negatively toward it (1996). Negative thinking can put up strongholds of self doubt in the minds of students that lead to self fulfilling prophecies about failure in math class (Pinzker, 2001). Sansone et al. discovered that students who were hardy did not need a strategy to succeed in finishing the task; less hardy students really needed that to help them finish (1999).

Purpose motivates someone to modify the activity because there is a driving force that makes the person shed a better light on his or her work (Sansone et al., 1999). People can control their level of interest in a project by manipulating the activity (Sansone et al., 1999). It is hard to keep interest in something that you do not really care about (Sansone et al., 1999). Changing your mindset or the actual activity makes persistence easier (Pinzker, 2001; Sansone et al., 1999). This ability to strategize impacts a student's ability to succeed when things are difficult (Sansone et al., 1999)

This ability to decide what they did also helped boost motivation (Sansone et al., 1999). Things related to the task also help increase desire to complete a task even if the 
"easiest option" is to quit the activity (Sansone et al, 1999). This happens when the person modifies the activity to make it less boring by changing the structure or the interpretation of the activity (Sansone et al., 1999). People that do this tend to not to perform as much quantity work, but they carry the work out longer than the test which leads to permanence of the behavior (Sansone et al., 1999). In the Wolford et al. (2001) study, although trained learning disabled students stopped several times to ask for feedback, they turned in more work than prior to the study.

If tutors and teachers want to motivate others, they must discover what is most important in each student's mind and then tailor their motivational energies there (Sansone et al., 1999). The motivator must outshine the toll that doing uninteresting work takes on the student (Sansone et al., 1999). Although including motivational strategies sometimes can cause decrease in production, deciding not to be concerned about motivation may cause the loss of psychological wellness and productivity all together (Sansone et al., 1999). As long as motivation is preserved, the desired goals will be met (Sansone et al., 1999). If teachers want to motivate students work cooperatively as a lifestyle, they must train students to create strategies to stay interested (Sansone et al., 1999). It is better to be able to make your self stick to something until you are able to change your view or your task to make it more interesting that to be conscientious and just do it because you know you should (Sansone et al., 1999). Students are more balanced and handle stressful situations better (Sansone et al., 1999). 
Handling stressful situations better can be accomplished by remembering “control, commitment, and challenge” (Sansone et al., 1999). Control = I can change my circumstances and anticipate what the consequences will be for my behavior. Commitment $=$ desire to be involved in exciting, meaningful activity. Challenge $=$ life's ups and downs are not fearful, but great opportunities to experience new things (Sansone et al., 1999). By realizing changes can be managed and dealt with, the problem is acknowledged and dealt with instead of focusing on feeling (Sansone et al., 1999). In the process, preventative work may need to be done to eliminate or limit the ability of the stress to affect the person by stick to the project and modifying the activity to make it more fun (Sansone et al., 1999). However, it is well worth the effort of putting the students in control of their academic success because it leads to a sense of ownership and responsibility on the part of the students (Pinzker, 2001).

\section{Grouping:}

Another vital part of the student success is the group in which they work. There are many ways in which they can be placed together. Ability grouping is a method of organizing students in classes based upon a certain instrument used to judge ability or academic growth (McGurk \& Pimentle, 1992). This is sometimes doubted as an appropriate method of determining class content (McGurk \& Pimentle, 1992). However, it proves to be quite effective as long as the teams are frequently adjusted so that one team does not consistently win over the others (Nichols \& Miller, 1994). 
Within-class grouping happens when students are place in groups within a classroom setting (Grossen, 1996). This is beneficial because the "peer tutoring” within the class is more convenient than outside of class tutoring (Roach, Paolucci-Whitcomb, Meyers \& Duncan, 1983). The groups working outside of class would demand greater amounts of time, additional preparation, and would require the teacher to expend greater energy to ensure the tutoring sessions occurred (Roach et al., 1983).

Size of the group also affects the success of the students. Abrami and Chambers assert that having students work in pairs or triads is most effective for younger children who do not have the cognitive level to process and evaluate others opinions (1996; Yackel et al., 1991). Collaborating in pairs, students develop a good working relationship much quicker (Slavin, 1996). The relationship is also enhanced when students are given a chance to share who they would like to work with, and they are more likely to succeed as groups (Artzt and Armour-Thomas, 1997). Teachers need to listen to their students' comments on the group's progress and cohesiveness (Artzt and ArmourThomas, 1997). Student input can help teachers to modify the learning environment to make it more beneficial.

Social issues contribute to determining the optimum mixture of students. Studies suggest that students work best when they are paired with someone of like gender (Slavin, 1996). Researchers have analyzed this and made group placements in different ways. Wilczenski et al. was concerned about personality and social connection with in the groups so they had students rate each other on how well they knew each other 
(Wilczenski et al., 1999; Stuart, 1994). Yackel et al. (1991) had the teachers give information on student personality so that beneficial pairings were made.

The success of group work according to Garthe et al. is also taking responsibility for one's role in the group, adding something beneficial, completing the task within the allotted time, and coming to an agreement on the solution (1998). It is a mixture of ensuring the job gets done while maintaining unity of the team (Yamaguchi, 2003). Everyone is nervous no matter what their ability level when the group begins to work together (Artzt and Armour-Thomas, 1997). Contribution of fellow teammates can be an area of concern. Some studies suggest that giving students specific roles in the group will enable them to contribute to the group (Abrami and Chambers, 1996; Slavin, 1996; Yackel et al., 1991). This builds into the "interpersonal motives" (Abrami and Chambers, 1996) and "self esteem” (Garthe et al., 1998). Parameters in working together build motivation to work together and assimilate the "values" working together (Abrami and Chambers, 1996). On the other hand, lack of definition of roles and participation leads to potential resentment and lessening of motivation (Abrami and Chambers, 1996).

In homogenous groups, low ability students feel more competent and the high ability students feel more competition (Grossen, 1996). Low socio-economic status individuals do better when working in a group together toward a goal. Equality gives confidence and wards off discouragement. However, the homogenous groups fail to provide additional knowledge necessary to teach lower level students to think more critically. The key question is to ask whether the child is in a group that will ensure 
his/her success (Grossen, 1996). If they lack the pre-knowledge, their placement must be reevaluated (Grossen, 1996).

Other research sides with Slavin (1996) on this issue of heterogeneous pairing because there is no clear proof that homogenous pairing is necessary for success (Abrami and Chambers, 1996; McGurk and Pimentle, 1992; Yackel et al., 1991). . However, the homogenous groups fail to provide additional knowledge necessary to teach lower level students to succeed. If they lack the pre-knowledge, their placement must be reevaluated (Grossen, 1996). In order to compensate, some have tried pairing lower level students together with success perhaps by supplying them with additional helps to make up for the lack of expert knowledge in the group ( Roach et al., 1983). ) Abrami and Chambers (1996) suggest the lack of cognitive equality could also be handled by adapting the materials given to the students to help them learn. Roach et al. (1983) claims that expertise is not necessary so tutors can be selected from people who would receive the most from the time helping someone else. As long they have a variety of people to consult to help them come to the right conclusion, they will succeed (Artzt and ArmourThomas, 1997; Hoek et al., 1999).

However one cannot ignore the other benefits gained by pairing students in heterogeneous groups. Wilczenski et al. states there is important impact stronger students make on their group's success; the success of their team was raised by their input (1999). High level students have the greatest potential to encourage discussion and planning in their groups (Artzt and Armour-Thomas, 1997). 
Slavin and others contend for the importance of grouping heterogeneously (Abrami and Chambers, 1996; Artzt and Armour-Thomas, 1997; McGurk and Pimentle, 1992; Stuart, 1994; Wilczenski, 1999). Typically, the more heterogeneous the group is in ability, the more planning and discussing that goes on to prepare for problem solving (Artzt and Armour-Thomas, 1997). The wider the range of ability, the more discussion and planning that occurs to complete the task (Artzt and Armour-Thomas, 1997). Groups should be able to function is the "expert-novice” roles where students help to build each other up in the area of problem solving (Pratt and Savoy-Levine, 1998; Stuart, 1994; Wolford et al., 2001). Students do better when they are given permission to be a part of the solution (Artzt and Armour-Thomas, 1997; Pratt and Savoy-Levine, 1998; Yackel et al., 1991).

Unfortunately, brighter students occasionally squander this opportunity by refusing to work with the group and focusing on their own completion of the task (Artzt and Armour-Thomas, 1997). Some researchers assert that the high level students feel like they are being taken advantage of and become frustrated when they are placed with slower student (Abrami and Chambers, 1996; Stuart, 1994). They also fear their openness to criticism, lack of control of the situation, and failure of task completion (Artzt and Armour-Thomas, 1997).

To change this negative behavior, higher level students need to be shown the advantages that they receive from working with lower level students (Hoek et al., 1999) 
Their focus on the problem to the ignoring of others and independent approach to problem solving will hurt the group in the end while negating the benefits possible through heterogeneous grouping (Artzt and Armour-Thomas, 1997). Teachers must keep a close watch on the groups and work to ensure that groups maintain discussions that encourage contributions from all students (Artzt and Armour-Thomas, 1997). These include general learning of information, arguing their point, categorizing information in an orderly fashion, and processing it (Kramarski et al., 2002). As long as students are not afraid of dealing with a mixture of opinions in a learning situation, they will succeed (Huber, 2003).

Higher ability students need some incentive to break down their negative reaction to being placed with less able students (Abrami and Chambers, 1996; Stuart, 1994). Some of their negative reaction is due to their inability to explain what seemingly come naturally to them (Hoek et al., 1999). Some of their negative attitudes may come from prejudice against the less-gifted or a sense being penalized by having to work with someone who is less able (Artzt and Armour-Thomas, 1997; Hoek et al., 1999). Though some educators are concerned about putting the higher level students at a disadvantage when they are paired with lower level students, studies have not proven this concern valid; other factors play into the concern (Slavin, 1996; Stuart, 1994). Hoek discovered that the higher the level of student benefit from learning to work in groups and problem solve (Hoek et al., 1999). Tutors may also learn to look at the problem in a new way as they work with their tutee (Wood and Wood, 1996; Leighton et al. 1989). They are able to benefit from the strategies and transfer them on a higher level (Hoek et al., 1999). 
However an educator chooses to group, the increase, decrease or stagnation of student growth will determine the effectiveness of the program (Grossen, 1996).

\section{Group Work (Discussion Parameters):}

Tutoring is a multifaceted task (Gutstein and Mack, 1999). Because the goal is understanding, and a certain amount of restructuring must happen for this to take place (Gutstein and Mack, 1999; Slavin, 1996). Studies that show that cooperative learning or peer tutoring made little or no difference in performance failed to consider the effect on training students in how to interact with their partners (Leighton et al., 1989; Wolford et al., 2001). When most of the teacher's time is spent on solving relational issues, learning the subject matter will not be given adequate time (Yackel et al., 1991). The relational problems occur because of the way students communicate with each other.

In group work, language exists for three different purposes. These include demonstration of feeling or communication for the purpose of task completion, attentiongetting, elaboration (Swann, 1999). Only humans are able to explain themselves to others; this is the difference between human and animal communication (Swann, 1999). According to Popper, it also has a fourth purpose which is disagreement which involves arguing and establishing alternatives (Artzt and Armour-Thomas, 1997; Swann, 1999). People are stretched cognitively by analyzing, pondering, and expanding concepts (Artzt and Armour-Thomas, 1997; Kramarski et al., 2002; Swann, 1999; Yackel et al., 1991). It can be uncomfortable at times and may take longer to accomplish (Huber, 2003). However, if the group is committed to the success of its members, is willing to submit to 
the alternating leadership of its members, and values people, then it will succeed in spite of differing opinions (Yamaguchi, 2003). As people practice, they will learn to better at working with others (Huber, 2003).

Disagreement proves to be positive when it makes people work to explain themselves to come to a point of mutual consent (Yackel et al., 1991). However, domination of one leader in a group to the exclusion of other ideas destroys the unity of the group and the motivation of its members (Yamaguchi, 2003).

Elaboration and interpersonal communication are key to learning (Kramarski et al., 2002; Swann, 1999; Slavin, 1996; Yackel et al., 1991). Ability to elaborate is created of over time as people participate in community with others (Swann, 1999; Yackel, 1991). In order to achieve community, participants should remember the main goals are acquiring knowledge, comprehending, and making positive changes (Yamaguchi, 2003). This elaboration can happen as an entire class or in a small group setting, but must be done according to the precedent established by the class (Wolford et al., 2001; Yackel et al., 1991). Higher level students must be careful to adequately explain their ideas so that their partners are not confused (Huber, 2003). “(G) ender, race, achievement level, and socio-economic background . . .” all impact the ability of teammates to clearly understand each other (Huber, 2003). Therefore elaboration requires training in "listening, explaining, encouraging, teaching, cooperating, and sharing” (Pinzker, 30, 2001). 
All members of the group can share in the success of the project by completion of the assignment, maintaining unity, and participating in edifying discussions (Yamaguchi, 2003). Teamwork is achieved as every child works so that each team member succeeds before they move on in the learning process (Slavin, 1996). Through this we are able to compete globally in the mathematical education area while still offering equal treatment to all students (Grossen, 1996).

In this process of elaboration, students learn to write a manuscript of their lives and interactions in their mind by recognizing problems, considering solutions to problems, and evaluating the ideas of others (Swann, 1999). Recruiting help from others involves students respectfully asking others to evaluate or point out mistakes made in their work (Wolford, Heward, and Alber, 2001). When it is done in a socially acceptable way, learning disabled students get the help they are looking for (Wolford et al., 2001).

Students do not automatically know how to interact to get the help they need; they must be shown how (Wolford et al., 2001). These acceptable forms of communication are: light touch, saying excuse me, or saying student's name, then waiting for a response, and asking for an evaluation of their work (Wolford et al., 2001). Positive responses from their peers will help prevent inappropriate acting out and social maladaptation (Wolford et al., 2001). These inappropriate actions would be interrupting, being too quiet or too boisterous, calling someone by the wrong name, inappropriate language, and asking non- academic questions (Wolford et al., 2001). Teaching students to recruit help positively is vital to their social and academic success and must be closely monitored 
(Wolford et al., 2001). There are rewards for the time spent on instruction in this area. Teaching students to ask for help in a polite way leads to higher quantity and quality work (Wolford et al., 2001).

When they initiate their program, teachers have to be comfortable enough with the new process to train the students, and enough training time had to be offered (Leighton et al., 1989). Sigel relates to instruction to the way students’ thought processes develop and the ability of students to learn (Wood and Wood, 1996). To teach someone to comprehend a concept involves bringing him or her through maze of questions that allow them to connect the pockets of prior knowledge that they have already established in their mind (Gutstein and Mack, 1999). The partners discuss the problem together complementing each other by challenging incorrect thinking and bringing up new ideas, and learning new concepts (Slavin, 1996; Yackel, 1991).

For learning to happen change must take place through increasing skills and coming up with new ideas through interaction with others (Swann, 1999; Yackel et al., 1991). It takes time and a series of small steps (Swann, 1999). Students, who learn more, fail more in the learning process (Pratt and Savoy-Levine, 1998; Yackel et al., 1991). As students progress in the process, they become better at comprehending and analyzing (Swann, 1999). They analyze data, hypothesize, and look for connections (Leighton, et al., 1989). Students must be taught to discover their own solution, work together, and be taught how to solve problems (Hoek et al., 1999; Gillies and Ashman, 1996; Yackel et al., 1991). This training in cooperation to reach a group goal ensures that 
the most learning possible will happen (Gillies and Ashman, 1996; Leighton et al., 1989). This includes teacher monitoring and correction to ensure positive cooperation in a discussion is happening (Yackel et al., 1991).

On the other hand, students who are in groups that are not taught to work well together may not be able to show their potential academically (Wilczenski et al., 1999; Gillies and Ashman, 1996). Studies should be performed to discover what makes a group work well together (Wilczenski et al., 1999). Then students should take time to develop good social skills so that they can become collaborative learners who are "listening to each other, providing constructive feedback on ideas; sharing tasks fairly; clarifying differences of opinion; trying to understand the other person's perspective; and monitoring and evaluating the group’s progress" (Gillies and Ashman, 1996). It is then the students' responsibility to see that the training is carried out in their own groups (Gillies and Ashman, 1996). Analyzing student behavior with in the group can help predict their success especially for special needs students (Wilczenski et al., 1999).

Students who discuss things with their groups well typically base their explanation on known theories or facts and are logical in their objectives and responses to problems being discussed (Wong et al, 2002; Akhras and Self, 2002). They are alerted to the possibilities in cognitive processing so they are prepared to assimilate knowledge in many different ways (Gillies and Ashman, 1996; Kramarski et al., 2002). Modeling helps by demonstrates over and over how to use resources and problem solve step by step (Hoek et al., 1999). This becomes stronger as the past and present knowledge is 
connected (Wong et al, 2002; Akhras and Self, 2002). For lower level students, there is a lack of this prior knowledge or they might not be ready to use the strategies used by stronger students (Hoek et al., 1999).

Experience is a great teacher if it is processed accurately (Akhras and Self, 2002). Students begin training by discussing what encourages people to want to contribute to the group (Gillies and Ashman, 1996). Effective group members try to include others in the discussion, responding with follow up questions, and explaining their method of finding an answer (Wilczenski et al., 1999; Hoek et al., 1999; Gillies and Ashman, 1996). They build each other up in the learning process (Gillies and Ashman, 1996). This is in stark contrast to those who drift away from the topic, do not listen well, and seek to control the group discussion (Wilczenski et al., 1999). Greater achievement was reached in some cases by those who succeeded at group interaction (Gillies and Ashman, 1996; Hoek et al., 1999; Wilczenski et al., 1999; Wolford et al., 2001). There is a direct connection between the students who did not do well at group interaction and those who did not do well on the posttest (Wilczenski et al., 1999).

Therefore it is important for the teacher to monitor group interaction (Gillies and Ashman, 1996). It is important to note if students are talking in a manner that does not create negative emotions within their group, working on their assignment together, and still accomplishing their part of the work, students have been successful at group work (Gillies and Ashman, 1996; Wolford et al., 2001). Students should listen and work 
together instead of tearing others down, refusing to comply with their group, or vying for first place with people in their own group (Gillies and Ashman, 1996).

Types of Communication:

Making sure that your teammates are able to participate, feel valued for their comments, and expressing group unity leads to a sense of community necessary for successful work (Gillies and Ashman, 1996). These are vital to the well-being of the group (Gillies and Ashman, 1996; Stuart, 1994). After instruction, students in the Gillies and Ashman study (1996) used this type of language more than those who remained without instruction. They realized the importance of this and were able to reach out more to their peers than those who used other methods of communication (Gillies and Ashman, 1996). Their elaboration was much more effective and they feel empowered to participate in the learning process (Gillies and Ashman, 1996; Kramarski et al., 2002). The unity was evident in their ability to make complete tasks as a group (Gillies and Ashman, 1996; Stuart, 1994). Yackel et al. (1991) recommends that the teacher encourage this behavior openly.

Hearing others ideas are important (Slavin, 1996). Vygotsky’s theory of learning is carried out in the socialization that promotes the exchange of ideas, evaluation of concepts and application of “problem solving” (Wilczenski et al., 1999; Pratt and SavoyLevine, 1998; Hoek et al., 1999; Leighton and Slavin, 1989; Swann, 1999; Yackel et al., 1991). Students build upon their prior knowledge and construct their own understanding of mathematics in their own way (Slavin, 1996). They along with their 
teammates work to explore mathematical concepts by connecting their previous discoveries with new ones and leading the students to attach them with symbols by attacking problems from many different angles (Slavin, 1996; Madden et al., 1997). Slavin (1996) presents a program that balances discovery learning and relevant experiences with establishing and understanding of mathematical concepts and maintaining skills.

On the other hand, words that promote self and ignore the needs of the group tend to drag down the ability to accomplish what is necessary (Gillies and Ashman, 1996; Stuart, 1994). These counterproductive comments hamper the progress of the group by devaluing people (Wolford et al., 2001) and their contributions (Gillies and Ashman, 1996; Stuart, 1994). They are intended to criticize and hurt others (Gillies and Ashman, 1996; Stuart, 1994). Yackel et al. (1991) recommends that the instructor lay out the expectations for the class, and then confront if the group is doing inappropriate things.

Training:

Roach et al. (1983) trained students for five days for 30 minutes by the special ed department. They showed by example and skits how to interact and give encouragement to their group (Roach et al., 1983). They were also taught a pattern of how to teach others and check for comprehension (Roach et al., 1983). During this time, the trainers worked on teaching students to: praise and interact in a manner that brings peace, staying at the process of learning, determining how fast to proceed in the lessons, how to teach their partner, understanding mathematical methods, how to communicate effectively with 
others their success or failure, testing for success, and keeping records (Roach et al., 1983; Yackel et al., 1991).

In Wolford et al.’s (2001) study, learning disabled students were coached on how to ask for help and check their problems with fellow students. Proper training made a big difference in their social abilities and people's willingness to accept them (Wolford et al., 2001). At the same time their peers were educated on how to truly help them by avoiding communication that hinders rather than encourage academic growth. This destructive "help” includes offering help when others do not need it (Gillies and Ashman, 1996).

This unnecessary help prevents students from taking responsibility for their growth in understanding concepts and hinders their intellectual development. Strong students are those who are actively involved in shaping their understanding of the world through their experience and interaction with others (Akhras and Self, 2002; Pratt and Savoy-Levine, 1998; Wolford et al., 2001; Yackel et al, 1991). They do not merely establish a theory; they also test it (Swann, 1999; Yackel et al., 1991). They question its truth and its merit because the theory is impacting society’s choices (Swann, 1999; Yackel et al., 1991).

The work being done and the supportive environment surrounding it intertwine as the learner seeks to process information and create a knowledge base (Akhras and Self, 2002; Pratt and Savoy-Levine, 1998; Hoek et al., 1999; Wolford et al., 2001; Yackel, 
1991). This knowledge may be an untapped resource or may need to be reconstructed to ensure consistent success (Gutstein and Mack, 1999; Pratt and Savoy-Levine, 1998; Wolford et al, 2001). What makes a person proficient is both knowledge and application (Swann, 1999). The extent of student learning is based on the content of discussion that goes on within the group (Wilczenski et al., 1999; Hoek et al., 1999). In Wong et al., the group of students that elaborated earned a better score than those who did not elaborate (2002; Kramarski et al., 2002). The need is to then transfer that ability to reason through problems to new situations (Wong et al, 2002). Self-elaboration is a learned skill that is not relegated to the intellectually strong; it can be taught to others (Wong et al, 2002). This training can be implemented as a part of the effective tutoring process.

As students begin to work together, there are some things that should be considered to ensure effectiveness. Frequent evaluation should be made to discern whether or not the principles of good tutoring are being followed.

A. Is the help needed?

Affirmation should be given. However explanation should not always be given. What students believe about themselves and their abilities controls the development of their academic success (Wong et al, 2002). Students are redirected with questions rather than explanations or correction (Gutstein and Mack, 1999). This ensures that students are not given too much help. It is better to give the child not as much assistance when they succeed and offer more assistance when the child struggles (Wood and Wood, 1996; 
Pratt and Savoy-Levine, 1998). An excessive amount of help tends to cripple students initiative to problem solve (Wood and Wood, 1996). The helper must be sensitive to the level of assistance needed in order to remove help when not necessary or increase it if need be (Wood and Wood, 1996; Pratt and Savoy-Levine, 2002; Hoek, van den Eeden, and Terwel, 1999).

A study of preschool children shows that they exhibit a greater affinity to those who aid them in this way (Pratt and Savoy-Levine, 1998). In Pratt and Savoy-Levine study, both the "contingent shift” and "moderate support” students liked the learning opportunity because of the freedom of expression for the most part though they did not like the times when they were shown what to do (1998).

Result have shown that children who are given "contingent” help scored significantly higher when their knowledge is tested than those who have been reminded of the direction orally or shown the process (Pratt and Savoy-Levine, 1998). Pratt and Savoy-Levine (1998) in their initial study gave three posttests: immediately, one week later, and a month later. In the second study, they gave an immediate test, one at one week, and one at one month, and the "contingent support” groups performed better than the other groups (Pratt and Savoy-Levine, 1998). The statistics show that giving help only as needed contributed to the length of time the residual effects of the tutoring remained and the ability to apply mathematical skill in other tasks (Pratt and SavoyLevine, 1998). 
Students who where just given the answers showed the least academic improvement, enjoyment, and desire to repeat the experience (Pratt and Savoy-Levine, 1998). Those who receive "moderate support” while initially appearing successful, did not continue to produce successful results long term because they did not have the established problems solving skills imbedded in their minds (Pratt and Savoy-Levine, 1998). The tutors in this case needed to release the control more to the student and allow them to fail if need be (Pratt and Savoy-Levine, 1998). The "contingent tutor" students were able to grasp the technique of solving problems to a greater extent (Pratt and SavoyLevine, 1998). They were given the ability to use the information to which they were exposed (Pratt and Savoy-Levine, 1998).

B. Is the explanation relevant?

To successfully shape a person's math knowledge, the tutor must test the tutee's knowledge continually throughout the session in order to meet the needs to the tutee (Gutstein and Mack, 1999). They must discuss the problem until an agreement has been reached for solving the problem (Kramarski et al. 231, 2002). Each person explains the reasoning behind their answers (Kramarski et al. 231, 2002).

This dialogue can be used to shape the kind and order of examples given to aid understanding (Gutstein and Mack, 1999). This is the job of the tutor to pass on their understanding of the problem and give their tutee their view of learning (Wood and Wood, 1996; Leighton et al., 1989). Wong et al. suggest that this elaboration be 
monitored closely to ensure its quality (Wong et al, 2002). This promises to be a challenge for the classroom teachers (Wong et al, 2002).

In the Pratt and Savoy-Levine study, when offering contingency tutoring, it is most important to make sure that when a child struggles, they are offered more than a reworded explanation (1998). The tutor needs to take over the task and demonstrate it again in a different way (Pratt and Savoy-Levine, 1998).

When a person does not understand, we can offer a "digression" to check their knowledge of a simpler, underlying concept (Gutstein and Mack, 1999). When they are successful, we can also do the same thing to link their knowledge to a more complex situation and lead them to greater understanding (Gutstein and Mack, 1999). Challenging the tutee's knowledge by making them prove that their answer is correct will also strengthen their math ability (Gutstein and Mack, 1999).

This method maybe frustrating for those who just want to find the answer. However, the understanding level is heightened for those who persevere (Gutstein and Mack, 1999).

Is the help timely?

Students must be given time to process the help they have been given. If they are special needs students in particular, they may need additional time to receive and understand what they have been taught (Wood and Wood, 1996). Studies show that 
students that succeed in learning gradually become less dependent on assistance (Wood and Wood, 1996; Pratt and Savoy-Levine, 1998).

Is the explanation understood?

Success of cooperative learning groups rise and fall on the process of the explanation (Abrami and Chambers, 1996). Students at all levels must participate to experience success (Abrami and Chambers, 1996). Mack uses concrete, real examples to help her students understand (Gutstein and Mack 1999). This can be like explaining the meaning of $1 / 4$ by asking how many quarters are in a dollar. Mack has her students say the problem first as they use manipulatives and then has them write it out symbolically (Gutstein and Mack, 1999). She is making the needed connection between the memorized method and the work being currently done (Gutstein and Mack, 1999). Accurate answers are used to lead to more challenging topics; these are challenges that positively effect students’ knowledge of the subject (Mack and Gutstein, 1999). This, however, can be harmful if the more in depth work confuses the student or makes them lost when returning to the topic at hand (Gutstein and Mack, 1999).

Is the student given time to work out the problem?

The level and type of assistance given by people is affected by the way they think and their environmental factors (Wood and Wood, 1996). This shapes the learner's pattern of thinking (Wood and Wood, 1996). Mothers that instruct using a method that fits their child's view of the problem tend to take control less and discuss the problem more openly with their child using questions that stimulate problem solving (Wood and 
Wood, 1996). True discussion involving both parties needs to be manipulated like this so that tutors can pinpoint the best way to ensure the cognitive results they desire (Wood and Wood, 1996). Training instructors in the way people learn proves beneficial toward achieving this goal (Wood and Wood, 1996). It involves working together with a great amount of structuring and feedback; eventually, it leads to responding only positively to the student's efforts (Wood and Wood, 1996).

There is a difference between interrupting a student and checking their understanding. Mack suggests that math problems be talked about (Gutstein and Mack, 1999). Expressing thought processes out loud after solving a problem, gives the tutor insight on how the tutee got their answer (Gutstein and Mack, 1999). She encourages students to figure out the correct answer when they get varying results for the same answer (Gutstein and Mack, 1999). She redirects them by questioning them about simpler concepts to help them figure out what they did wrong (Gutstein and Mack, 1999). She never directly corrects them (Gutstein and Mack, 1999). Instead students are left to discover on their own that they have made an error, and as a result, they continue to seek out answers (Wood and Wood, 1996). It puts a more positive spin on learning by increasing self-efficacy and challenging the student to take more responsibility for learning and completion of the product (Wood and Wood, 1996). The instructor is there just to keep tutee on task and to make positive comments about the progress being made so that students are prepared to take work independently (Wood and Wood, 1996). 
Does the student do the practice work?

Holding student responsible for meeting the requirement for their cooperative learning group goals and demonstrating their knowledge challenges students to do the things that make achievement possible and avoid ones that sabotage their efforts (Slavin, 1996). It prevents one child from doing all of the work (Slavin, 1996), and ensures that students are actually able to do the work (Wilczenski et al., 1999). Students should not have the ability to use other's knowledge without learning to figure solutions and think critically; cooperative learning has no lasting impact in these situations (Wilczenski et al., 1999).

What else effects the tutoring?

Labeling the problem can be a difficult issue at times. Some people are more gifted at interpreting what a child is lacking to complete their understanding (Pratt and Savoy-Levine, 1998). They are able to tell when a child does not understand and can modify their tutoring accordingly (Pratt and Savoy-Levine, 1998).

In the same way, students have differing abilities when it comes to communicate their lack of understanding. Some students are also able to communicate their educational needs more effectively (Pratt and Savoy-Levine, 1998). Some times students with special needs struggle to communicate their need in a socially acceptable way (Wolford et al., 2001). They must be taught how to politely ask for help, patiently wait, and what kind of questions to ask (Wolford et al., 2001). 
As growth occurs in this area, students are more effective in participating in the learning process. It is at times hard to watch intellectual and social skills struggling to develop. However, if a consistent instruction program is followed it leaves room for growth; the students will thrive in the experience of gaining knowledge. 


\section{CHAPTER III: PROJECT AND RESULTS}

\section{Presentation of the Problem}

As the research has shown, the peer tutoring form of cooperative learning can be quite effective when elaboration is modeled and required. Webb encourages educators to consider the interaction occurring in the group setting, and shape it so that it benefits all of the participants in a statistically significant way (1991). She believes that the inconclusive data comes from research that has not considered the group conversation (Webb, 1991).

\section{Project Background}

After the author saw the line of students waiting for extended periods of time just to have math questions answered, she began searching for a way to help students while making better use of educational time. During this year prior to the project, the author had divided her fourth grade math students up into groups of four and allowed them to ask each other questions before coming to her for help in completing their problem set. The first person in the team that received $100 \%$ on the assignment was allowed to be the checker for fellow teammates and was sometimes recruited to help check other teams. The checkers were told not to tell the answers. The team with the highest score in a half hour period of time consistently through out the nine weeks was given a party. The only requirement for team members was that they receive a passing score on the problem set. 
Grades came from the tests and the homework. Students were highly motivated to become the checker for their group. Normally more reserved students would shine as they filled the position of checker. Students struggling in math obtained their highest grades during this period. Another motivation for the students to finish early was that those who accomplished their problem set early were able to work on other work.

The team concept cut down on the waiting period for help, and team spirit was built by rewarding the teams with the highest grades on their problem sets. However, some students still continued to struggle in math. Part of the problem seemed to be that the explanations given during the work time were not adequate and everyone was not contributing because of the group size.

The summer before the next school year, the author began researching the peer tutoring type of cooperative learning and began to formulate the appropriate group work policy that was necessary to encourage greater success. She examined the students' math achievement test scores from the previous year and arranged the students by pairing low and high students together and medium students with each other. After doing so, the author asked the third grade teacher who had the students the year before to rank the students according to math ability. The author found her results matched her coworker's assessment. For the incoming fifth grade students, she consulted both their math achievement test scores and her grade book from the year before to ensure her placements were accurate. 
The author also considered personality. Appropriate pairing was possible because she had the incoming fifth grade students as fourth graders during the previous year. Having watched the incoming fourth grade students during recess and lunchroom duties, she also tried to place those with compatible personalities together. This was to prevent one student from being overbearing to the point of keeping the other from contributing to the group work.

With the groups in place, the author posed the question of whether or not peer tutoring would benefit her students. She wanted to best meet the needs of her students in the discipline of mathematical learning.

\section{Presentation of the Hypothesis}

In the interest of defining the growth in learning achieved by the students from the beginning to the end of a mathematical unit taught using cooperative learning, the researcher tested the hypothesis:

$\mathrm{H}_{0}$ : There will be no significant increase in the student's classroom test scores from the time they took the pretest until they took the posttest.

The author also wanted to test whether gender played a role in the achievement of students on the Saxon Math pretest and posttest taken in class. This theory was tested using this hypothesis:

$\mathrm{H}_{0}$ : There will be no significant difference between the female and male students' scores in their level of achievement on unit pretests and posttests during the use of peer tutoring.

In order to discover if she had reached the goal of developing her students 
mathematical abilities through cooperative learning, the author performed a study to test the hypothesis:

$\mathrm{H}_{0}$ : There will be no significant difference in the students' standardized testing scores when comparing the students' scores achieved while in a peer tutoring setting with the scores of students achieved in a traditional classroom learning program with out the benefit of paired peer tutoring.

The author also wanted to consider whether gender played a role in the achievement of the students. She asserted that it would not in her fourth hypothesis:

$\mathrm{H}_{0}$ : There will be no statistically significant difference between the male and female students' scores in their level of achievement on standardized tests prior to and during the use of peer tutoring.

\section{Subjects}

During the 2002-2003 school year, Calvary Christian School in Bellefontaine, OH had 176 students. The students are part of a rural community. They come from upper to middle class families. Many of the children have parents who work in factories or professional offices. A few parents farm. All of the students participating in the study were Caucasians ranging from age eight to twelve.

There was only one fourth grade class of 14 students. There were 8 boys and 6 girls. One of the male fourth graders was not at Calvary Christian the previous year and therefore had no compatible data to demonstrate academic progress. The child was still placed with a partner according to the percentile on a different achievement test score. In the end there were 13 students whose scores were used to examine the success of the project. 
There was only one fifth grade class of 25 students. There were 10 male students and 15 female students. One of the female fifth grade students was at the sixth grade level in math, and a male student moved away in the first month of school so neither child participated in the study. There were also four fifth graders ( 1 male and 3 female) who had no compatible standardized test data from the previous year to assess. In the final count, there were 19 fifth graders who had test scores to analyze. All 23 were still placed in groups; the author looked at their previous achievement test scores to determine a place. Though four had scores that came from standardized tests that were not the Stanford Achievement Test, the scores gave enough of a picture of their math ability to place them in an appropriate group. The odd number of students forced the researcher to form one of the groups using 3 members.

The author divided the students into groups of two based on achievement level. She placed two medium math students together, and a high math student with a low math student. The fourth grade continued in this pattern until Thanksgiving and then returned to a more individualistic system where the students came to the teacher for assistance. The fifth grade finished out the school year using the mixed ability groups.

Until fourth grade, students used the ABEKA math curriculum. Starting in fourth grade, students switched to Saxon math. In Saxon math there is a test form A and B. The researcher used these as a pretest and posttest. They were administered prior to and at the end of each section. The student's actual grade was taken from the posttests and 
quizzes that were administered. In addition, students were given participation points for completing their assigned group work that factored into their grade.

The students were required to work either the even or odd problems in an assignment until they had all of the answers correct or until the period was over. They were to check their answers with each other. When they had come to an agreement on all of the answers, they came to the researcher to have them checked. If they were correct, they were rewarded with time for reading or opportunity to complete their other required work for the day. If they were not, the researcher would help them find their mistake and send them back to correct it.

The author requested permission of the school administrator before initiating the study. At an open house shortly before the new school year began, the study was discussed with parents.

\section{Variables}

Independent Variables

The independent variable is the peer tutoring situation where students are grouped in mixed ability groups for the high and low students and in similar ability groups for those with medium ability. There was not another class of fourth $(n=13)$ and fifth grade $(n=19)$ so the control group was the same students a year prior to the project. The same sample and variable was used to test the other hypotheses. 


\section{Dependent Variables}

Gender and the achievement of students were the two dependent variables. A test was run to eliminate the possibility that gender would influence the results of the test. There were 11 girls and 8 boys in fifth grade that participated in the study. There were 7 boys and 6 girls in fourth grade that participated in the study.

\section{Procedures}

After the approval of the school administrator and the announcement to parents at the open house, the students were informed of the study and that this was to help the author complete her degree. They were told that they would work out math problems together and test separately. The students were anticipating working together. The students were told who their partner would be with the exception of one fifth grade group who had three group members. They were given instruction on how to work together and discuss the answers they figured out. Students were told to be prepared to show each other how they got their answers. They were taught to be respectful during discussion. Honesty and integrity were stressed to the students. They were told the tests would reveal whether or not they had truly been working instead of just giving their answers to their partner.

Students were given the pretest and their scores were recorded. The next day the researcher discussed the new section with the students and did the practice problems with them. After the instruction was given in the classroom, the students were given the problem set to do, and sent to a larger room so that they could spread out. The author

circulated answering questions. She also sat at a podium checking work and answering 
questions for part of the time. The students completed the even numbered problems if the number of the problem set was even, and they did the odd numbered problems if the number of the problem set was odd.

Occasionally they did speed drills and quizzes independently also. When the section of problem sets was done, the students were given the posttest and their scores were recorded. After that, they were given the next pretest and the whole process began again.

In April, the students were given the tenth edition of the Stanford Achievement Test. The results were compared with their achievement scores on last year's test which was the ninth edition of the Stanford Achievement Test.

\section{Results}

The author analyzed the pre and posttest scores that came from giving the fourth grade students the Saxon Math prepared tests. They were compared using SPSS Pearson's Correlation to see if the results were statistically significant. The results were inconsistent showing that 4 of the 6 tests obtained statistically significant increases in

achievement at the 0.01 level. One test demonstrated statistically significant increases at the 0.05 level, and another test showed no statistically significant increase in achievement. 
Table 1

Correlations between Fourth Grade Scores Achieved on the Saxon Math Pretest and Posttest

\begin{tabular}{llll}
\hline Source & $\underline{\text { Pearson's Correlations }}$ & $\underline{\text { Sig. (1-tailed) }}$ & Sig. (2-tailed) \\
\hline Test 1 & $.703^{* *}$ & .003 & .005 \\
Test 2 & $.746^{* *}$ & .001 & .002 \\
Test 3 & .306 & .144 & .287 \\
Test 4 & $.744^{* *}$ & .001 & .002 \\
Test 5 & $.577^{*}$ & .015 & .031 \\
Test 6 & $.849^{* *}$ & .000 & .000 \\
\hline
\end{tabular}

** Correlation is significant at the 0.01 level.

* Correlation is significant at the 0.05 level.

The author also ran a One-Way ANOVA on the fourth grade pretest and posttest scores to examine the role gender might have played in student achievement on the unit tests. The null hypothesis was that students would improve their scores equally as well regardless of gender. The alternate hypothesis stated that one gender would score not equal to the other. The hypothesis was null at the .01 level. However, this changed at the .05 level for only one of the tests. All students saw success in their scores regardless of gender with the exception of Test 3 A. There was a significant difference in achievement based on gender during that test at the .05 level. 
Table 2

One-Way Analysis of Variance for Differences between Gender and Achievement On Fourth Grade Classroom Tests.

\begin{tabular}{|c|c|c|c|c|c|}
\hline Source & $\begin{array}{l}\text { Sum of } \\
\text { Squares }\end{array}$ & $\mathrm{df}$ & $\begin{array}{l}\text { Mean } \\
\text { Square }\end{array}$ & $\mathrm{F}$ & Sig. \\
\hline Test $1 \mathrm{~A}$ & 1.621 & 1 & 1.621 & .203 & .660 \\
\hline Test $1 \mathrm{~B}$ & .095 & 1 & .095 & .061 & .810 \\
\hline Test 2 A & .787 & 1 & .787 & .056 & .816 \\
\hline Test 2 B & .214 & 1 & .214 & .043 & .839 \\
\hline Test $3 \mathrm{~A}$ & 36.214 & 1 & 36.214 & 8.779 & $.012^{*}$ \\
\hline Test $3 \mathrm{~B}$ & 5.357 & 1 & 5.357 & 1.343 & .269 \\
\hline Test $4 \mathrm{~A}$ & 48.214 & 1 & 48.214 & 4.451 & .057 \\
\hline Test $4 \mathrm{~B}$ & 11.006 & 1 & 11.006 & 1.211 & .293 \\
\hline Test $5 \mathrm{~A}$ & .482 & 1 & .482 & .056 & .816 \\
\hline Test 5 B & 17.357 & 1 & 17.357 & 1.752 & .210 \\
\hline Test $6 \mathrm{~A}$ & 14.292 & 1 & 14.292 & 2.254 & .159 \\
\hline Test 6B & 5.006 & 1 & 5.006 & .529 & .481 \\
\hline
\end{tabular}

${ }^{*} \mathrm{p}<.05 .{ }^{* *} \mathrm{p}<.01$.

The author took the Stanford Achievement Test scores for the fourth graders and compared them using SPSS Pearson's Correlation to see if the results were statistically significant between scaled scores of the group work and traditional work of the previous year. For the fourth grade students, there was a correlation at the 0.01 level on the 2tailed test when their third and fourth grade scores were compared. There was also as 
statistically significant correlation between the fourth and the fifth grade scores showing that improvement continued even after their participation in the study on group work.

\section{Table 3}

Correlations between Math Achievement Test Scores for 2002-2003 Fourth Graders and Other Years

\begin{tabular}{|c|c|c|c|}
\hline Source & $\underline{\text { Pearson's Correlation }}$ & Sig. (1-tailed) & Sig. (2-tailed) \\
\hline $\begin{array}{l}\text { Third Grade Scaled Score } \\
(n=13)\end{array}$ & $.867 * *$ & .000 & .000 \\
\hline $\begin{array}{l}\text { Fifth Grade Scaled } \\
\text { Score }(n=13)\end{array}$ & $.823 * *$ & .000 & .001 \\
\hline
\end{tabular}

** Correlation was significant at the 0.01 level (1-tailed and 2-tailed).

The researcher also ran a One-Way ANOVA on the fourth grade scores to see if gender had an effect on their math achievement test scores. The null hypothesis was that boys and girls would score equally well on the test. The alternative hypothesis stated that one gender would score not equal to the other. The hypothesis was null because the $\mathrm{p}>$.05. All students scored well regardless of their gender.

Table 4

One-Way Analysis of Variance for Differences between Gender and Achievement for Fourth Grade Class

\begin{tabular}{lllll}
\hline Source & $\underline{\mathrm{Df}}$ & $\underline{\mathrm{SS}}$ & $\underline{\mathrm{MS}}$ & $\underline{\mathrm{F}}$ \\
\hline Between groups & 1 & 282.881 & 282.881 & .428 \\
Within groups & 12 & 5046.833 & 420.569 & \\
Total & 13 & 5329.714 & & \\
\hline
\end{tabular}

Note: $F$ was not significant at $a=.05$. 
The author analyzed the pre and posttest scores that came from giving the fifth grade students the Saxon Math prepared tests. They were compared using SPSS Pearson's Correlation to see if the results were statistically significant. The results showed students' scores obtained statistically significant increases in achievement at the 0.01 level on 3 of the 6 tests. Inconsistency showed in the fact that 2 had negative correlations and 1 had a correlation that was not statistically significant. However, the negative correlations were very close to zero so there really was not much correlation at all.

Table 5

Correlations between Fifth Grade Scores Achieved on the Saxon Math Pretest and Posttest

\begin{tabular}{llll}
\hline Source & \multicolumn{1}{l}{ Pearson's Correlations } & Sig. (1-tailed) & Sig. (2-tailed) \\
\cline { 2 - 3 } Test 1 & -.096 & .331 & .662 \\
Test 2 & $.823^{* *}$ & .000 & .000 \\
Test 3 & .343 & .055 & .109 \\
Test 4 & $.896^{* *}$ & .000 & .000 \\
Test 5 & -.067 & .381 & .762 \\
Test 6 & $.546^{* *}$ & .004 & .007 \\
** Correlation is significant at the 0.01 level. & \\
$*$ Correlation is significant at the 0.05 level.
\end{tabular}

The author also ran a One-Way ANOVA on the fifth grade pretest and posttest scores to examine the role gender might have played in student achievement on the unit tests. The null hypothesis was that students would improve their scores equally well 
regardless of gender. The alternate hypothesis stated that one gender would score not equal to the other. The hypothesis was null at the .01 level. However, on Test 6 B, the results were significant at the .05 level. Therefore, it is not possible to say completely that gender did not effect their achievement of academic success on the Saxon Math classroom tests.

Table 6

One-Way Analysis of Variance for Differences between Gender and Achievement on Fifth Grade Classroom Tests.

\begin{tabular}{cccccc}
\hline Source & $\underline{\text { SS }}$ & $\underline{\mathrm{df}}$ & $\underline{\mathrm{MS}}$ & $\underline{\mathrm{F}}$ & $\underline{\text { Sig. }}$ \\
\hline Test 1 A & 7.558 & 1 & 7.558 & .673 & .421 \\
Test 1 B & .447 & 1 & .447 & .133 & .719 \\
Test 2 A & 6.242 & 1 & 6.242 & .348 & .562 \\
Test 2 B & 3.914 & 1 & 3.914 & .224 & .641 \\
Test 3 A & .933 & 1 & .933 & .154 & .699 \\
Test 3 B & 3.732 & 1 & 3.732 & 1.092 & .308 \\
Test 4 A & 26.764 & 1 & 26.764 & 1.569 & .224 \\
Test 4 B & 33.590 & 1 & 33.590 & 2.342 & .141 \\
Test 5 A & 6.715 & 1 & 6.715 & 1.794 & .195 \\
Test 5 B & .580 & 1 & .580 & .123 & .730 \\
Test 6 A & 1.025 & 1 & 1.025 & .129 & .723 \\
Test 6B & 19.056 & 1 & 19.056 & 6.375 & $.020 *$
\end{tabular}

${ }^{*} \mathrm{p}<.05 .{ }^{* *} \mathrm{p}<.01$. 
The author took the Stanford Achievement Test scores for the fifth graders and compared them using SPSS Pearson's Correlation to see if the results were statistically significant between scaled scores of the group work and traditional work of the previous year. For the fifth grade students, there was no correlation at the 0.01 level on the 2tailed test when their fourth and fifth grade scores were compared. However, there was a statistically significant correlation at the 0.01 level on the 2-tailed test between the fifth and the sixth grade scores showing that improvement showed up the following year after the year of group work.

Table 7

Correlations between Math Achievement Test Scores for 2002-2003 Fifth Graders and Other Years

\begin{tabular}{|c|c|c|c|}
\hline Source & Pearson's Correlation & Sig. (1-tailed) & Sig. (2-tailed) \\
\hline $\begin{array}{l}\text { Fourth Grade Scaled } \\
\text { Score }(\mathrm{n}=19)\end{array}$ & .384 & .052 & .105 \\
\hline $\begin{array}{l}\text { Sixth Grade Scaled Score } \\
(\mathrm{n}=20)\end{array}$ & $.861^{* *}$ & .000 & .000 \\
\hline
\end{tabular}

The researcher also ran a One-Way ANOVA on the fifth grade scores to see if gender had an effect on their math achievement test scores. The null hypothesis was that boys and girls would score equally well on the test. The alternative hypothesis stated that one gender would score not equal to the other. The hypothesis was null because the $\mathrm{p}>$.05. The students scored equally well regardless of gender. 
Table 8

One-Way Analysis of Variance for Differences between Gender on Achievement Tests in Ratio and Proportion Unit for Fifth Grade Class

\begin{tabular}{llllll}
\hline Source & $\underline{\mathrm{SS}}$ & $\underline{\mathrm{df}}$ & $\underline{\mathrm{MS}}$ & $\underline{\mathrm{F}}$ & $\underline{\text { Sig. }}$ \\
\hline Between & 170.050 & 1 & 170.050 & .329 & .572 \\
Groups & & & & \\
Within & 10839.429 & 21 & 516.163 & & \\
Groups & & & & & \\
Total & 11009.478 & 22 & & & \\
\hline
\end{tabular}

Note: $\mathrm{F}$ was not significant at $\mathrm{a}=.05$.

In light of the results, the author believes that the fourth grade benefited from the group work during mathematics. Their results showed definite progress according to the standardized test, but there was some inconsistency in the achievement shown in the classroom tests. The results of the classroom test comparison call into question why there was growth in the achievement test scores. The researcher wonders if the growth in achievement happened in spite of the time spent working in groups. Gender did not play a role in standardized test achievement. Further research needs to be done to show whether the single score difference based on gender is a revelation of an underlying problem in classroom achievement.

The fifth grade results did not show a significant growth from fourth to fifth grade on the math portion of the achievement test. However, there was significant growth in fifth to sixth grade. There is also an inconsistency in the significance of the growth in 
learning shown in the fifth grade classroom tests. Gender did not play a role in the success of the fifth grade students with the exception of one classroom test. Further research should be done to determine if this there is an underlying problem. The reason for the $5^{\text {th }}$ grade lack of notable progress will be discussed in the following summary. 


\section{CHAPTER IV: SUMMARY AND CONCLUSIONS}

In spite of the inconsistent results, the author believes there is still much to learn from the study. Although standardized tests showed no significant increase in learning for the fifth grade students, progress was shown in the fourth grade students on their achievement tests. However, the test results are inconclusive because of variables that may have skewed the analysis of the data. The doubt that the educational success stems from cooperative learning also comes from inconsistent results of the analysis of the growth in achievement between pretests and posttests for both the fourth and fifth grade students.

Unfortunately, there were some uncontrollable externals that may have affected the results. First of all the smaller sample size and the lack of the ability to have a control group of the same grade level may have affected the statistical analysis. Second, the achievement test the school previously used was changed from the ninth edition to the tenth edition. The fifth grade students had also spent the last semester of their fourth grade year in some form of group work. There was no way to compare the growth rate intellectually caused by their group work and traditional classroom work in mathematics. There was no pure sample from the previous year where they had not participated in group work. 
The change between math curriculums may have affected the fourth grade students’ ability to have sufficient prior knowledge to help each other. There is always an adjustment when a new curriculum is used. Fourth grade seems to be that year of adjustment. Toward the end of the trial period of cooperative learning, students began to struggle with the new methods and concepts being introduced. Prior to that their learning had enough of an element of review in it for them to be able to help each other. As a result, more scaffolding was required by the teacher to help them reach the next level of achievement.

The benefits of the fifth grade were that they had already completed a year of the Saxon math, had practice working together last year, and understood how to be successful at group work. There was also a good mix of academically strong boys and girls who could be leaders. In the smaller fourth grade, there was a lack of that particularly among the girls. The fourth grade students seemed to be closer together in academic level. In order to have a sufficient knowledge base, there needs to be a greater difference in academic ability (Webb, 1991).

In further studies, larger sample size and control on the students' exposure to cooperative learning in mathematics may help to better determine the success the peer tutoring program. Other research should be done to isolate the benefits of various forms of communication between partners. Elaboration appears to be the key to learning on the part of both students. However, students must be monitored closely otherwise they may 
be able to hide their inability to understand until the test if their partner has given them the answers to the problem set.

The question then seems to be how to keep the students on the path of achieving success at completing mathematical problems while ensuring students communicate in an educationally beneficial way. The researcher's suggestion is that further studies be a cooperative effort of two researchers. One who focuses on the elaboration done in the pairs through instruction, supervision, and immediate feedback on group interaction. While the other researcher focuses on the academics of the pairs through initial instruction, checking work on the spot, scaffolding for groups that struggle to find an answer, and administering the tests. Through this combined effort, greater attention can be paid to the qualitative and quantitative aspects of cooperative learning. This will lead to pinpointing of the most beneficial approach to cooperative learning.

It is the author's desire to see all students grow and gain what they need from their mathematical education setting. Reading the studies done by other researchers revealed to the author the importance of scaffolding to students' academic success in mathematics. It gives them a chance to grow gradually in the ability to solve problems. Even as a teacher, it is so tempting to reveal the method of solving the algorithm instead of helping the student to work out their own strategy. Students perform higher academically when they are given the opportunity to explore on their own and given only as much help as they need when they require it. Personality plays into this. Careful matching of students will enable success even on the part of the shy and reserved ones. 
Rewarding the students is also a delicate matter. It must be handled in a way that encourages achievement by all. Students can overrun each other in attempt to win the prize for their team. They may be tempted to give answers just to finish ahead of other groups or to ensure they have the highest score. They may become impatient with others adding stress to the learning environment. The need for quick answers can also keep partners from taking the time to give more detailed explanations. Careful plans must be made to prevent students from simply doling out answers.

Another area of need that became apparent was the unity in the group. Sometimes students would become frustrated with each other's actions including off-task behavior. The author would discuss the problem and reinstruct the class in appropriate group work behavior. Overt training, modeling, and accountability achieved the best response from the students. Cooperative learning fails for lack of training.

After the study was over, the fifth grade class continued on in groups as they did in the study. The class did change partners. Partners were reassigned based on ability level and personality as they were initially. The students enjoyed working in groups for the most part. After the study, the fifth grade class was good about making suggestions of how to make the group work more successful.

At the end of the study, the author feels that there is a need for more time for mathematical instruction and practice in the classroom. The author and the students at 
times felt rushed to complete the work. The author believes math is something that should be done at school. The time at home should be spent in extra practice for the test if that would be beneficial. Although working on math at school would be more desirable, for some students additional help is needed at home even when they are participating in a program like peer tutoring in the classroom.

Cooperative learning in mathematical education has great promise to extend children's capacity to expand their problem solving skills and grow intellectually. The author desires that her work would spur on others to examine specifically appropriate and beneficial forms of group communication. Through careful planning and testing of elaboration techniques, the controversy over the effects of group work in mathematics can be laid to rest. 


\section{REFERENCES}

Abrami, P.C. \& Chambers, B. (1996). Research on cooperative learning and achievement: comments on slavin. Contemporary Educational Psychology, 21, 70-79.

Akhras, F.N. \& Self J. A. (2002). Beyond intelligent tutoring systems: situations, interactions, processes and affordances. Instructional Sciences, 30, 1-30.

Artzt, A.F., \& Armour-Thomas, E. (1997). Mathematical problem solving in small groups: exploring the interplay of students' metacognitive behaviors, perceptions, and ability levels. Journal of Mathematical Behavior, 16, 63-74.

Beetham, S., McLennan, C., \& Witucke, C. (1998). Improving social competencies through the use of conflict resolution and cooperative learning. Unpublished theses, St. Xavier University, 1-66.

Chizhik, A.W. (2001). Equity and status in group collaboration: learning through explanations depends on task characteristics. Social Psychology of Education, 5, $179-200$.

Clemenz, S. E. (2002). The effects of peer tutoring on the attitudes of nondisabled peers. ERIC Document 309 123, 1-39.

Collins, K. M. T. \& Onwuegbuzie, A. J. (2001). Effect of an after-school tutorial program on academic performance of middle school students at-risk. Little Rock, AR: Mid-South Educational Research Association. (ERIC Document Reproduction Service No. ED 467717)

Davidson, N. \& Kroll, D. L. (1991). An overview of research on cooperative learning related to mathematics. Journal for Research in Mathematics Education, 22(5), 362-365.

Endsley, W. R. (1980). Peer Tutorial Instruction. Englewood Cliffs, NJ: Educational Technology Publications.

Evans, M. D., (1997). Acamletics: A team approach to learning. Principal, 76, 52-3. 
Fasko, S. N. (1994). The effects of a peer tutoring program on math fact recall and generalization. Los Angeles, CA: The American Psychological Association. (ERIC Document Reproduction Service No. ED 383 542)

Fuchs, L.S., \& Fuchs D. (2001) Principles for sustaining research-based practice in schools: A case study. Focus on Exceptional Children, 33 (6), 1-14.

Fuchs, L.S., Fuchs, D., Hamlett, C.L., \& Appleton, A.C. (2002). Explicitly teaching for transfer: effects on the mathematical problem-solving performance of students with mathematical disabilities. Learning Disabilities Research and Practice, 17 (2), 90-106.

Fuchs, L.S., Fuchs, D., Hamlett, C.L., Phillips, N.B., Karns, K., \& Dutka, S. (1997). Enhancing students; Helping behavior during peermediated instruction with conceptual mathematical explanations. Elementary School Journal, 97, 223-249.

Fuchs, L.S., Fuchs, D., \& Karns, K. (2001). Enhancing kindergartens’ mathematical development: effects of peer-assisted learning strategies. The Elementary School Journal, 101 (5), 495-510.

Fuchs, L.S., Fuchs, D., Kazdan, S., Karns, K., Calhoon, M.B., Hamlett, C.L., \& Hewlett, S. (2000). Effects of workgroup structure and size on student productivity during collaborative work on complex tasks. Elementary School Journal, 100, 83-212.

Garthe, W., McDonald, M., Poremba, K., Schmidt, C., \& Summers, P. (1998). Improving student social skills. Unpublished thesis, St. Xavier University, 1-79.

Gillies, R.M. \& Ashman, A.F. (1996). Teaching collaborative skills to primary school children in classroom-based work groups. Learning and Instruction, 6 (3), 187200.

Griffin, M. M., \& Griffin, B.W. (1998). An investigation of the effects of reciprocal peer tutoring on achievement, self-efficacy, and test anxiety. Contemporary Educational Psychology, 23, 298-311.

Grossen, Bonnie (1996). How should we group to achieve excellence with equity. Eugene: National Center to Improve the Tools of Educators. (ED 460 467)

Gutstein, E. \& Mack, N.K. (1999). Learning about teaching for understanding through the study of tutoring. Journal of Mathematical Behavior, 17, 441-465.

Hoek, D, van den Eeden, P., \& Terwel, J. (1999). The effects of integrated social and cognitive strategy instruction on the mathematics achievement in secondary education. Learning and Instruction, 9, 427-448. 
Hong, H. (1996). Effects of mathematics learning through children's literature on math achievement and dispositional outcomes. Early Childhood Research Quarterly, 11, 477-494.

Huber, G.L. (2003). Processes of decision-making in small learning groups. Learning and Instruction, 13, 255-269.

Jacques, N., Wilton, K., \& Townsend, M. (1998). Cooperative learning and social acceptance of children with mild intellectual disability. Journal of Intellectual Disability Research, 42 (1), 29-36.

Kramarski, B., Mevarech, Z.R., \& Arami, M. (2002). The effects of metacognitive instruction on solving mathematical authentic tasks. Educational Studies in Mathematics, 49, 225-250.

Leighton, M. S., Slavin, R.E., \& Davidson, N. (1989) Achievement effects of individual, small group, and cooperative learning strategies on math problem-solving. Baltimore: Center for Research on Elementary and Middle Schools. (ED 332862)

Madden, N. A., Slavin, R.E., \& Simmons, K. (1997). Mathwings early indicators of effectiveness. Baltimore, MD: Center for Research on the Education of Students Placed At Risk.

McGurk, E. K. \& Pinmentle, J.A. (1992). Alternative instructional grouping practices. Rensselaer, IN: St. Joseph College (ERIC Document Reproduction Service No. ED 353 279).

McMillan, J.H. (2003). The relationship between instructional and classroom assessment practices of elementary teachers and student scores in high-stakes tests. 1-18.

Mc Millan, J.H., Myran, S., \& Workman, D. (2002). Elementary teachers’ classroom assessment and grading practices. Journal of Educational Research, 95 (4), 203213.

Mevarech, Z. R. (1985). The effects of cooperative mastery learning strategies on mathematics achievement. Journal of Educational Research, 78(6), 372-377.

Nattiv, A. (1994). Helping behavior and math achievement gain of students using cooperative learning. Elementary School Journal, 94, 285-297.

Nichols, J.D. \& Miller, R.B. (1994). Cooperative learning and student motivation. Contemporary Educational Psychology, 19, 167-178.

Pinzker, V. (2001). Increasing the engagement and understanding of concepts in mathematics. Unpublished master's thesis, St. Xavier University, Chicago, Illinois. 
Pratt, M.W. \& Savoy-Levine, K.M. (1998). Contingent tutoring of long-division skills in fourth and fifth graders: experimental tests of some hypotheses about scaffolding. Journal of Applied Developmental Psychology, 19 (2), 287-304.

Rees, D.I., Brewer, D.J., \& Argys, L.M. (2000). How should we measure the effect of ability grouping on student performance. Economics of Education Review, 19, 17-20.

Roach, J.C., Paolucci-Whitcomb, P., Meyers, H., \& Duncan, D. (1983). The comparative effects of peer tutoring in math by and for secondary special needs students. The Pointer, 27 (4), 20-24.

Sansone, C., Wiebe, D.J., and Morgan, C. (1999). Self-regulating interest: the moderating role of hardiness and conscientiousness. Journal of Personality, 67 (4), 701-733.

Slavin, R.E. (1996). Research on cooperative learning and achievement: what we know, what we need to know. Contemporary Educational Psychology, 21, 43-69.

Slavin, R.E. (1987). Cooperative learning: student teams ( $2^{\text {nd }}$ ed.). Washington, D.C.: National Education Association.

Slavin R. E., et al. (1996). Every child, every school: success for all. Thousand Oaks, California: Corwin, Press.

Steinbring, H. (1997). Epistemological investigation of classroom interaction in elementary mathematics teaching. Educational Studies in Mathematics, 32, 4992.

Stuart, M. (1994). Effects of group grading on cooperation and achievement in two fourth grade math classes. Elementary School Journal, 95(1), 11-21.

Swann, J. (1999). What happens when learning takes place. Interchange, 30 (3), 256282.

Utay, C. \& Utay, J. (1997). Peer-assisted learning: The effects of cooperative learning and cross-age peer-tutoring with word processing on writing skills of students with learning disabilities. Journal of Computing in Childhood Education, 8 (2-3), 165-185.

Waldron, K. \& Allen, L. V. Z. (1999). Successful strategies for inclusion at the middle level. Middle School Journal, March, 18-28.

Webb, N. (1991). Task-related verbal interaction and mathematics learning in small groups. Journal for Research in Mathematics Education, 22 (5), 366-389. 
Wilczenski, F. L., Bontrager, T., Ventrone, P., \& Correia, M. (1999). Assessing group process during collaborative problem solving. Boston, MA: The American Psychological Association. (ERIC Document Reproduction Service No. ED 434 156)

Wolford, P.L., Heward, W.L., \& Alber, S.R. (2001). Teaching middle school students with learning disabilities to recruit peer assistance during cooperative learning group activities. Learning Disabilities Research \& Practice, 16 (3), 161-173.

Wong, M.F., Lawson, M.J., \& Keeves, J. (2002). The effects of self-explanation training on students' problem solving in high-school mathematics. Learning and Instruction, 12, 233-262.

Wood, D. \& Wood, H. (1996). Commentary Contingency in tutoring and learning. Learning and Instruction, 4 (6), 391-397.

Yackel, E., Cobb, P., \& Wood, T. (1991). Small-group interactions as a source of learning opportunities in second-grade mathematics. Journal for Research in Mathematics Education 22(5), 390-408.

Yamaguchi, R. (2003). Children's learning groups: a study of emergent leadership, dominance, and group effectiveness. Chicago, IL: American Educational Research Association. (ERIC Document Reproduction Service No. ED 476661)

Zukauskas, J.A. (1998). Improving cooperative behavior through the use of social skills instruction. Master's thesis, St. Xavier University, Chicago, Illinois. 


\section{VITA}

Shelley Renee Grimm comes from a family of three girls. She was saved at the age of five and felt the Lord directing her to serve Him. She taught fourth grade for 6 years in Bellefontaine, Ohio. She loved being a teacher, youth leader, and camp counselor.

It was during this time that she knew the Lord was leading her to become a missionary to Nicaragua. She is currently on prefield ministry and looks forward to the time when she will be teaching Nicaraguan street children and taking them to camp. 